\title{
LA GUERRA DE LOS MUNDOS: REALIDAD VS. FORMALISMO JURÍDICO O EL PODER DE LA INTERPRETACIÓN (A PROPÓSITO DE LA SENTENCIA TJUE DE 27 DE FEBRERO DE 2018, WESTERN SAHARA CAMPAIGN UK, C-266/16)
}

\author{
JAVIER A. GONZÁLEZ VEGA ${ }^{1}$ \\ Universidad de Oviedo \\ jvega@uniovi.es
}

\begin{abstract}
Resumen
La sentencia de 27 de febrero de 2018 del TJUE en el asunto C-266/16 se ha pronunciado a favor de la validez del Acuerdo y el Protocolo de pesca UE-Marruecos de 2006 y 2013 en contra de los argumentos expresados por el Abogado General M. Whatelet en sus conclusiones del pasado mes de enero. Sin embargo, pese a ello, el Tribunal ha excluido su aplicación a los espacios marinos aledaños al Sáhara Occidental en contra de lo sostenido por el Consejo y la Comisión, así como por algunos Estados intervinientes en el proceso. Para ello el Tribunal ha propugnado que la aplicación del acuerdo en esas circunstancias violaría las normas generales del Derecho internacional que la UE ha de respetar -y, particularmente, el derecho del pueblo del Sáhara Occidental a la libre determinación. La conclusión del Tribunal, aparentemente fundada en el principio de integración sistémica (art. 31.3.c) CV), se sustenta sin embargo en una visión rígidamente formalista del caso -realizando una abstracción absoluta respecto de las circunstancias reales del supuesto- y abona una interpretación selectiva de las reglas de interpretación de los tratados contenidas en el art. 31 de la Convención de Viena, además de ajena a la realidad. El esfuerzo del Tribunal por postular una solución que salvaguarde la credibilidad política de la acción exterior de la UE en un supuesto particularmente controvertido le lleva a olvidarse de las exigencias inherentes al desempeño de su función jurisdiccional.
\end{abstract}

\section{Palabras clave}

Alcance de la cuestión prejudicial: control de los acuerdos concluidos por la UE; Acuerdo y protocolo UE-Marruecos en materia de pesca; interpretación de los acuerdos: principio de integración sistémica; vinculación de la UE al derecho internacional: principio de libre determinación de los pueblos; Sáhara Occidental

THE WAR OF THE WORLDS: REALITY VS. LEGAL FORMALISM OR THE POWER OF INTERPRETATION (ON THE EUCJ RULING OF 27 FEBRUARY 2018, WESTERN SAHARA CAMPAIGN UK, C-266/16)

\footnotetext{
Abstract

EUCJ Ruling of 27 February 2018, C-266/16, affirms the validity of the EU-Morocco Agreement 2006 and its 2013 Protocol on fisheries against the views purported by the Advocate General M. Whatelet in its previous conclusions of last January. However, at the same time the Court rejects the application of the aforesaid agreements to the waters contiguous to Western Sahara claimed by EU institutions and some member States, insofar as the validity of such agreements is founded in its conformity with general norms of International Law - namely the right of self-determination of the people of Western Sahara- that excludes

${ }^{1}$ Catedrático de Derecho internacional público y Relaciones internacionales de la Universidad de Oviedo. El trabajo se enmarca en el proyecto "Obstáculos a la movilidad de personas en los nuevos escenarios de la UE", DER2017-86017-R, financiado por el MINECO.
} 
such territorial extension in spite of the facts. Notwithstanding, the judgment of the Court, presumedly founded in the principle of systemic integration (art. 31.3.c) VCLT), lies in a strictly formal appreciation of the case and its selective approach to the Vienna Convention rules regarding treaty interpretation (art. 31) remains aside of the reality. Trying to save the political credibility of EU foreign action in a specially controverted issue, the Court affords a solution that misleads its judicial function.

\section{Key words}

Extent of preliminary rulings: judicial control of EU agreements; EU-Morocco agreement and protocol on fisheries; interpretation of treaties: principle of systemic integration; EU's subjection to international law: self-determination of peoples; Western Sahara.

\section{LA GUERRE DES MONDES: REALITÉ C. FORMALISME JURIDIQUE OU LE POUVOIR DE L'INTERPRÉTATION (À PROPOS DE L'ARRÊT CJUE DE 27 FÉVRIER 2018, WESTERN SAHARA CAMPAIGN UK, C-266/16)}

\section{Résumé}

L'arrêt CJUE du 27 février 2018 dans l'affaire C-266/16 prône la validité de l'Accord et du Protocole de pêche UE-Maroc de 2006 et 2013, en rejetant les arguments exprimés par l'Avocat Général M. Whatelet dans ses conclusions du passé janvier. Or la Cour a exclu en même temps leur application aux espace maritimes contiguës au Sahara Occidental malgré les propos soutenus par le Conseil et la Commission, ainsi que quelques États membres intervenant dans la procédure. En agissant de cette manière, la Cour affirme que l'application des accords dans ces circonstances risquait de violer les normes générales du droit international que l'Union est tenue de respecter -notamment, le droit du peuple du Sahara Occidental à disposer de lui-même. Pourtant, la conclusion de la Cour, apparemment fondée sur le principe d'intégration systémique (art. 31.3.c) CV), relève d'une approche rigidement formaliste de l'affaire -déployant une argumentation qui démontre une abstraction absolue de ses réelles données- et décèle d'une approche sélective aux règles concernant l'interprétation des traités prévues à l'article 31 de la Convention de Vienne, qui tourne le dos à la réalité. Les efforts de la Cour pour assurer une solution qui garantisse la crédibilité politique de l'action extérieure de l'Union dans une affaire particulièrement controversé la mènent à oublier les exigences inhérentes à son métier juridictionnel.

\section{Mots clés}

Étendue du renvoi préjudiciel: contrôle des accords conclus par l'UE; accord et protocole UEMaroc concernant la pêche; interprétation des traités: principe d'intégration systémique; respect par l'Union du droit international: droit des peuples à disposer d'eux-mêmes; Sahara Occidental

I. INTRODUCCIÓN. II. DE NUEVO EL SÁHARA EN LUXEMBURGO: LOS PROCEDIMIENTOS JUDICIALES RELATIVOS A LA CUESTIÓN. III. EL CONTEXTO DE LA PRESENTE DECISIÓN: EL MARCO JURÍDICO DE LAS "CODICIADAS AGUAS" DEL SÁHARA OCCIDENTAL: 1. La soberanía permanente del Sáhara occidental sobre sus recursos marinos. 2. La regulación de los espacios marítimos del Sáhara. 3. El ejercicio de las competencias sobre los espacios marinos: los acuerdos de pesca (1975-2013). IV. LAS POSICIONES DEL ABOGADO GENERAL WHATELET, DE LAS INSTITUCIONES Y DE LOS ESTADOS MIEMBROS. V. EL ENFOQUE DEL TRIBUNAL: UNA VISIÓN FORMALISTA DEL ASUNTO: 1. La competencia del 
Tribunal para controlar la validez de un acuerdo internacional en vía prejudicial. 2. ¿Un análisis en cuanto al fondo? El peculiar control judicial del respeto del Derecho internacional apud art. 31.3.c) de la Convención de Viena. 3. La imposible aplicación de los acuerdos pesqueros al Sáhara Occidental: ¿una inexistente intención común de las partes? VI. EL TRIBUNAL Y LA GUERRA $D E$ LOS MUNDOS: CONCLUSIONES Y ELUCUBRACIONES.

A Ahmed Jafari, In memoriam

Quod non est in codice non est in mundo

\section{INTRODUCCIÓN}

Cuando en otro lugar abordábamos el comentario sobre las conclusiones del Abogado General (en lo sucesivo, AG) M. Whatelet en el asunto cuya resolución por el Tribunal de Justicia de la Unión Europea (TJUE en adelante) analizamos en la presente contribución (González Vega, 2018:12), éramos conscientes de las dificultades que comportaba "predecir el futuro" y como era de esperar la Sentencia dictada por el Tribunal de Luxemburgo el pasado 27 de febrero ha desvirtuado -o al menos ha dejado sin atender- algunas de las cuestiones que allí apuntábamos. Ciertamente ha sido así porque -una vez más- el Tribunal ha eludido seguir la vía marcada por el AG y entrar en el examen de algunas cuestiones de indudable relevancia suscitadas por aquél -particularmente la cuestión acerca de la invocabilidad por los particulares de las normas del derecho internacional ante el TJUE ${ }^{2}$. A ello también ha contribuido el que el Tribunal haya decidido apostar por una lectura ciegamente formalista de la cuestión a examen, rehusando seguir el planteamiento del AG en relación con el tema, sobre lo que tendremos ocasión de incidir. No es menos cierto, sin embargo, que dos afirmaciones realizadas entonces se mantienen en pie: una, con la que encabezábamos nuestra anterior aportación, relativa a las implicaciones de la concepción de la UE como una Unión de Derecho conforme a las exigencias inherentes al respeto del derecho internacional por parte de la UE; conclusión que se mantiene incólume en la decisión del pasado febrero, dada su asunción por la curia de Luxemburgo, tal como habrá lugar a advertir. La otra, con la que concluíamos nuestra contribución, relativa a los "tiempos interesantes" que abre la nueva decisión del TJUE y sobre los que, breve y prospectivamente, incidiremos también en el presente trabajo.

El objeto de esta aportación es analizar críticamente la decisión dictada por el Tribunal, pero ello nos obligará a reculer pour mieux sauter. Por de pronto será necesario que situemos la presente decisión en el marco de los diferentes procedimientos que han venido

\footnotetext{
$2 \mathrm{Al}$ respecto vid. infra, V.1. El enfoque restrictivo seguido por el Tribunal no es nuevo tal como revelara el precedente asunto relativo al Sáhara Occidental (STJUE de 21 de diciembre de 2016, Consejo/Front Polisario, C-104/16 P, EU:C:2016:973). En ella, el TJUE había declinado abordar la legitimación del Frente Polisario limitándose a constatar su falta de legitimación in concreto en base a la ausencia de afectación directa. Ello ha dado pie a que, frente a lecturas más fervorosas, se admita que la previa interpretación favorable del Tribunal General (STG de 10 de diciembre de 2015, Front Polisario/Consejo, T-512/12, EU:T:2015:953) se mantenga hasta tanto una futura decisión del Tribunal de Justicia la descarte (Hilpold, 2017:914).
} 
desarrollándose ante los órganos jurisdiccionales de la UE a propósito de la cuestión del Sáhara Occidental, una saga judicial que en principio no culmina con la sentencia objeto del presente comentario. Por otra parte, será preciso que abordemos sucintamente la perspectiva histórica del conflicto -el "mundo real"- sobre el que ha venido a incidir el TJUE -en concreto las relaciones pesqueras entre la UE y el Reino de Marruecos y su proyección sobre los espacios marinos del Sáhara Occidental- para analizar seguidamente las posiciones expresadas por los intervinientes en el procedimiento -incluido el AG Whatelet ${ }^{3}$ - que, aunque antagónicas, resultaban plenamente consecuentes con aquel. Luego será el momento de analizar y valorar el enfoque y las afirmaciones vertidas por el Tribunal -el "mundo formalista" por el que discurre- para concluir efectuando unas consideraciones pro futuro a la luz de la situación derivada de la sentencia y de las expectativas de los actores interesados, no todos ellos -como es sabido- participantes en el litigio.

\section{DE NUEVO EL SÁHARA EN LUXEMBURGO: LOS PROCEDIMIENTOS JUDICIALES RELATIVOS A LA CUESTIÓN}

Como es sabido, la cuestión del Sáhara Occidental irrumpía en el foro de Luxemburgo a raíz de la interposición de un recurso por parte del Frente Polisario en 2013 que tenía por objeto la anulación de la Decisión 2012/497/UE del Consejo, de 8 de marzo de 2012, relativa a la celebración del Acuerdo en forma de Canje de Notas entre la Unión Europea y el Reino de Marruecos sobre medidas recíprocas de liberalización del comercio de productos agrícolas, productos agrícolas transformados, pescado y productos de la pesca, en la medida en que dicha Decisión aprobaba la aplicación del Acuerdo al Sáhara Occidental ${ }^{4}$. Se inicia así un periodo en el que las cuestiones relativas a los recursos del territorio se convierten en el centro del debate judicial dadas las relaciones privilegiadas que en el orden económico la UE mantiene con Marruecos, susceptibles de incidir en los recursos naturales existentes en el Sáhara. El despliegue por parte del Frente Polisario de una estrategia -claramente deudora de la jurisprudencia Brita acogida por el TJUE a propósito de la cuestión palestina ${ }^{5}$ - se sitúa así en el origen de lo que va a conformar una inusual e inesperada saga judicial ${ }^{6}$.

\footnotetext{
${ }^{3}$ Conclusiones de 10 de enero de 2018, EU:C:2018:1.

${ }^{4}$ Aunque como recordaba el Abogado General en sus Conclusiones (pto. 72, n. 43), un asunto de finales de los años 90 ya había tenido incidencia en el tema de la pesca en el Sáhara Occidental (Auto TPI de 30 de abril de 1999, Pescados Congelados Jogamar/Comisión, T-311/97, EU:T:1999:89, apdo. 6), naturalmente ni por su entidad ni por sus implicaciones, poseyó el impacto de los asuntos presentes.

${ }^{5}$ Sentencia de 25 de febrero de 2010, Brita, C-386/08, EU:C:2010:91. Sobre esta decisión véanse, entre otros, Cortés Marín, 2010: 626-631; Díez Peralta, 2010; Gordon y Pardo, 2015: 74-90; Guarino, 2012: 691-717; Harpaz y Ruinson, 2010: 551-570.

${ }^{6}$ Las iniciativas judiciales del Frente Polisario se despliegan también en otras latitudes como revela la reciente decisión del Tribunal Supremo de la provincia del Cabo Oriental (Sudáfrica), de 23 de febrero de 2018, que ha reconocido la propiedad saharaui sobre un cargamento de fosfatos con destino a Nueva Zelanda, previa retención en un puerto sudafricano del buque marroquí que los transportaba (Cfr. "Sudáfrica falla a favor del Sáhara en pleito por cargamento de fosfato", diario La Vanguardia, 23 de febrero de 2018, accesible en <http://www.lavanguardia.com/politica/20180223/441008377915/sudafrica-falla-a-favor-del-sahara-enpleito-por-cargamento-de-fosfato.html> consultado el 10 de mayo de 2018).
} 
La demanda del Frente Polisario dará pie a una primera decisión del Tribunal General, la sentencia de 10 de diciembre de $2015^{7}$, en la cual ésta instancia realizaba 2 interesantes apreciaciones, una relativa a la legitimación procesal del Frente Polisario para interponer un recurso de anulación -arrumbando las conocidas tesis restrictivas sobre el particular- ofreciendo una lectura que, aunque criticable en cuanto a su fundamentación, llevaba a su segunda conclusión, la posibilidad de ejercer un control sobre los actos de las instituciones relativos a la celebración del acuerdo que juzgaba inaplicables -y por ende el mismo acuerdo- a los productos procedentes del Sáhara Occidental. La consabida reacción de las instituciones y de los Estados miembros -presionados además por el Reino de Marruecos- no se hizo esperar, procediendo casi inmediatamente a la interposición de un recurso de casación ante el TJUE que propiciaba una nueva decisión, la sentencia de 21 de diciembre de $2016^{8}$, en la cual la suprema instancia jurisdiccional de la UE, anulaba la previa decisión del Tribunal General, pero -contra lo esperado- aunque afirmaba la plena validez del acuerdo en liza, estimaba que éste no resultaba aplicable al territorio del Sáhara Occidental ${ }^{9}$.

Sin embargo, no había de acabar aquí el periplo saharaui por la curia de Luxemburgo, dado que tanto para el Frente Polisario como para las organizaciones de la sociedad civil que vienen desplegando actividades de solidaridad con el pueblo saharaui, restaba un frente fundamental a acometer y a decir verdad el más emblemático: la validez del Acuerdo de cooperación de 2006 y de su Protocolo de aplicación de 2013 relativos a la pesca, pues en ellos la explotación de los recursos haliéuticos del Sáhara Occidental constituye su fundamental razón de ser. En esa tesitura, tanto el Frente Polisario -de nuevo interponiendo un recurso de anulación ante el Tribunal General ${ }^{10}$ - como las organizaciones de la sociedad civil, a través del desarrollo de litigios ante los órganos jurisdiccionales nacionales propiciaban un nuevo asalto, que en éste último caso, merced al planteamiento de diversas cuestiones prejudiciales por parte del tribunal nacional -en el caso un órgano jurisdiccional británico ${ }^{11}$ - llevaban de nuevo el tema a la jurisdicción europea. Aunque la primera acción judicial se encuentra aún sub iudice -paralizada en tanto se resolvía el presente asunto- ha sido la segunda la que ha dado lugar a la sentencia que comentamos. En ella, como tendremos ocasión de advertir, el TJUE, fundado en gran medida en los argumentos expuestos en su decisión de 2016, sostiene la vigencia de los Acuerdos en causa, aunque de nuevo excluye de su aplicación el territorio del Sáhara Occidental y concretamente sus espacios marinos aledaños, en los que, sin embargo, vienen desarrollándose tradicionalmente las actividades de explotación pesquera más significativas.

\footnotetext{
${ }^{7}$ Sentencia de 10 de diciembre de 2015, cit.

${ }^{8}$ Sentencia de 21 de diciembre de 2016, cit.

${ }^{9}$ Sobre estas decisiones, además de Hilpold, 2017, véase Delile, 2017: 178-183; Díez Peralta, 2017; Dubuisson y Poissonier, 2016: 599-634; El Ouali, 2017: 923-951; Ferrer Lloret, 2017: 15-64; Fleury Graff, 2016: 263-291; Gosalbo Bono, 2016: 21-77; Hummelbrunner y Prickartz, 2016: 19 y ss.; Kassoti, 2017 a: 339-356; Kassoti, 2017 b: 23-42; Milano, 2017: 953-966; Odermatt, 2017: 731-738; Peifert, 2017: 1031-1048; Poissonier y Dubuisson, 2016: 503-522; Rasi, 2017: 967-975; Simon y Rigaux, 2016: 5-11; Simon y Rigaux, 2017: 5-9; Soroeta Liceras, 2016; Soroeta Liceras, 2017: 73-93.

10 TG, Front Polisario/Consejo, T-180/14. Demanda interpuesta el 14 de marzo de 2014 (DO C 184, 16 de abril de 2014, p. 33).

11 Petición de decisión prejudicial planteada por la High Court of Justice (England \& Wales), Queen's Bench Division (Administrative Court) - Reino Unido, el 13 de mayo de 2016 - Western Sahara Campaign UK/Commissioners for Her Majesty's Revenue and Customs, Secretary of State for Environment, Food and Rural Affairs (DO C 260, 18 de julio de 2016, pp. 31-32). Sobre el procedimiento ante los tribunales británicos que se encuentra en el origen del caso véase Hart, 2015.
} 


\section{EL CONTEXTO DE LA PRESENTE DECISIÓN: EL MARCO JURÍDICO DE LAS "CODICIADAS AGUAS" DEL SÁHARA OCCIDENTAL}

Como hemos señalado la cuestión suscitada ante el TJUE arranca de la prolongada explotación de los recursos pesqueros del Sahara Occidental a través del marco establecido desde 1986 entre la, entonces, Comunidad Económica Europea y el Reino de Marruecos a través de los sucesivos -y casi ininterrumpidos- acuerdos de pesca; un marco normativo cuya difícil compatibilidad con las reglas del derecho internacional no había pasado desapercibido a casi ningún observador avisado, excepción hecha obviamente de aquellos que suscribían tout court los endebles argumentos del Reino alauita.

\section{LA SOBERANÍA PERMANENTE DEL SÁHARA OCCIDENTAL SOBRE SUS RECURSOS MARINOS}

$\mathrm{Y}$ es que el derecho internacional, en consonancia con el principio de libre determinación, asigna un conjunto de derechos de contenido económico a los pueblos sometidos a dominación colonial -entre los que se encuentra aún hoy en día el Sáhara Occidental. Esos derechos se vinculan con la soberanía permanente sobre los recursos naturales reconocida tanto a los Estados como a los pueblos y se proyectan, lógicamente, sobre los espacios marinos aledaños al territorio no autónomo. De hecho, poco más tarde de la afirmación del derecho de los pueblos coloniales a la libre determinación ${ }^{12}$, se forjó en el ámbito de Naciones Unidas el principio de la "soberanía permanente" "de los pueblos y naciones" a sus riquezas y recursos naturales, la cual se proclamaba en la capital Resolución de la Asamblea General de las Naciones Unidas 1803 (XVII), de 14 de diciembre de 1962, debiendo ejercerse "en interés del desarrollo nacional y del bienestar de la población del respectivo Estado. Es cierto, sin embargo, que los ulteriores desarrollos del principio primaron una concepción que apuntaba, en una terminología vacilante, ante todo a los Estados $^{13}$. No obstante, la Resolución AG 3201 (S-VI), de 1 de mayo, adoptada el mismo año que la "Carta de Derechos y deberes económicos de los Estados" -e inserta en el marco del denominado "Nuevo Orden Económico Internacional"- se refería específicamente a los pueblos coloniales como beneficiarios de esos derechos ${ }^{14}$. De hecho, las consiguientes implicaciones en el plano de la responsabilidad internacional respecto de los recursos expoliados durante el periodo de dominación colonial confortaban la inequívoca titularidad de esos derechos en favor del pueblo colonial, durante el periodo de dominación (Pastor Ridruejo, 2009: 278). Por otra parte, la vocación omnicomprensiva respecto de los recursos comprendidos en la soberanía permanente así afirmada incluye

\footnotetext{
12 Si bien la dimensión económica del derecho aparecía presente ya en el Preámbulo de la Resolución 1514 (XV) y sería reiterada en la posterior Resolución 2625 (XXV).

${ }_{13}$ Pastor Ridruejo recuerda que si bien la Resolución AG 2158 (XXI), de 25 de noviembre de 1966, utilizaba el ambiguo término "países" -ya empleado en la Resolución 1514 (XV) de consuno con el término pueblo para aludir a las situaciones coloniales- Resoluciones posteriores como la 3171 (XXVIII) de 17 de diciembre de 1973, y, particularmente, la emblemática Resolución 3281 (XXIX), de 12 de diciembre de 1974, en la que se incluye la "Carta de derechos y deberes económicos de los Estados", se limitaban a contemplar en exclusiva a éstos (Pastor Ridruejo, 2009: 277).

14 Resolución AG 3201 (S-VI), Declaración sobre el establecimiento de un nuevo orden económico internacional, párr. 4, apdo. f); accesible en <http://www.un.org/es/comun/docs/?symbol=A/RES/3201(SVI) $>$.
} 
obviamente los existentes en el medio marino y los consiguientes derechos sobre dicho espacio en favor del pueblo sometido a dominación colonial.

Corolario de lo anterior, el nuevo derecho del mar que veía la luz coetáneamente también afirmaba tales derechos al abordar la regulación de los nuevos espacios marinos. En tal sentido, en el curso final de los trabajos de la III Conferencia de Naciones Unidas sobre el Derecho del Mar, la Resolución III relativa a la relación de la Convención con el art. 73 de la Carta -atinente al régimen de los territorios no autónomos- adoptada por la misma el 30 de abril de 1982 y anexa al Acta Final de la Conferencia, afirmaba:

En el caso de que un territorio cuyo pueblo no haya alcanzado la plena independencia u otro régimen de autonomía reconocido por las Naciones Unidas, o de un territorio bajo dominación colonial, las disposiciones concernientes a derechos e intereses con arreglo a la Convención se aplicarán en beneficio del pueblo del territorio con miras a proveer a su bienestar y desarrollo; ${ }^{15}$

En cuanto al Sáhara Occidental, ya durante el periodo colonial, la ONU había insistido en la necesidad de respetar sus Resoluciones sobre el particular ${ }^{16}$. En tal sentido, la Resolución AG 3292 (XXIX), de 13 de diciembre de 1974 reiteraba su invitación:

a todos los Estados a que observen las resoluciones de la Asamblea General relativas a las actividades de los intereses económicos y financieros extranjeros en el Territorio, y a que se abstengan de contribuir con sus inversiones o su política de inmigración al mantenimiento de la situación colonial en el Territorio

De hecho, en línea con este planteamiento, incluso España -como potencia administradora del territorio- se planteó adoptar medidas en relación con esta exigencia. Así, el non nato Estatuto del territorio del Sahara, aprobado el 4 de julio de 1974 por la Asamblea General (Yemaa) del territorio, tras asegurar "el libre ejercicio de derecho de autodeterminación del territorio" (art. 2), garantizaba "al pueblo saharaui la exclusiva propiedad de sus riquezas y recursos naturales y el disfrute de sus beneficios". ${ }^{17}$

Desde entonces, pese a los avatares, los derechos del pueblo del Sáhara Occidental se mantienen incólumes, tal como afirmara en 2002 el controvertido dictamen Corell sobre el que volveremos más adelante ${ }^{18}$.

\section{LA REGULACIÓN DE LOS ESPACIOS MARÍTIMOS DEL SÁHARA}

Durante el periodo de la colonización española no se adoptaron medidas específicas en relación con los espacios marítimos de la colonia, por lo que la regulación vigente era la dictada con carácter general para nuestro país. Consecuentemente, ésta se concretaba inicialmente en las "venerables" disposiciones de la Real Cédula de diecisiete de diciembre de mil setecientos sesenta y demás Leyes y disposiciones sobre extensión de las aguas jurisdiccionales españolas, dictadas al socaire de las contingencias internas y externas.

\footnotetext{
15 Acta Final de la Tercera Conferencia de las Naciones Unidas sobre Derecho del Mar, Anexos, p. 223; accesible en < http://www.un.org/depts/los/convention_agreements/texts/acta_final_esp.pdf > .

${ }^{16}$ Así, las Resoluciones 2929 (XXI), de 20 de diciembre de 1966; 2354 (XXII), de 19 de diciembre de 1967; 2428 (XXIII), de 18 de diciembre de 1968; 2591 (XXIV), de 16 de diciembre de 1969; 2711 (XXV), de 14 de diciembre de 1970; 2983 (XXVII), de 14 de diciembre de 1972; 3162 (XXVIII), de 14 de diciembre de 1973.

${ }^{17}$ Art. 3. El texto del proyecto puede consultarse en Carro Martínez, 1976: 32-38.

18 Vid. infra, 5.C).
} 
Esta situación, como es sabido fue modificada por la Ley 20/1967, de 8 de abril, sobre extensión de las aguas jurisdiccionales españolas a doce millas, a efectos de pesca ${ }^{19}$, merced a la cual se fijaba como criterio de delimitación a estos efectos la línea de bajamar escorada a lo largo de "todas las costas de soberanía española" (art. 2). Es cierto, no obstante que la "condición jurídica distinta" del territorio no autónomo del Sahara Occidental podría llevar a sostener una interpretación distinta, pero no existen elementos que induzcan a pensar que este planteamiento estuvo presente en la redacción de la Ley española, por lo que esta era pues la situación en el momento del abandono del territorio por parte de España.

Por lo que respecta al periodo que se inicia en 1975 conviene advertir que, aunque Marruecos venía planteando sus reivindicaciones sobre el territorio del Sáhara, no adoptó medida ninguna en relación con dicho espacio con anterioridad a su ocupación ilegal del mismo $^{20}$. De hecho, éstas se adoptarán tras los denominados “Acuerdos de Madrid” que contemplaban un reparto del territorio entre Marruecos y Mauritania, implicando la cesión de Saguia el Hamra al primero y Río de Oro al segundo. Sin embargo, como también es sabido, en el caso mauritano, la ocupación del territorio -sostenida a duras penas en el curso del conflicto armado con el Frente Polisario- concluyó en 1979 con la firma del acuerdo de paz de 5 de agosto de 1979 y la cesión del territorio a este último ${ }^{21}$. También es notorio que la iniciativa fue pronto neutralizada por Marruecos que extendía su ocupación al territorio cedido por Mauritania, proclamando formalmente su anexión el 14 de agosto de 1979.

En el ínterin, no obstante, Marruecos y Mauritania formalizaron en el plano bilateral su anexión del territorio a través del Convenio relativo al trazado de la frontera de Estado establecida entre la República Islámica de Mauritania y el Reino de Marruecos, hecho en Rabat el 14 de abril de 1976, conforme al cual tomaban como referencia el paralelo 24 norte, tanto para la delimitación de la frontera terrestre como de la plataforma continental $^{22}$. Asimismo, la ocupación del territorio del Sáhara en 1976 también movió a Marruecos y Mauritania a abordar la cooperación en materia de explotación de los recursos pesqueros del banco sahariano, concluyendo un Acuerdo de cooperación económica, también de 14 de abril de $1976^{23}$.

19 BOE, núm. 86, 11 de abril de 1967. Dichas previsiones se complementaban con el Decreto de 26 de diciembre de 1968 (BOE, núm. 17, 20 de enero de 1969) sobre extensión a 12 millas en materia fiscal de las aguas jurisdiccionales españolas.

${ }^{20}$ De hecho, el Dahir de 21 de julio de 1975 se limita en exclusiva al territorio del Reino, aunque incluye los espacios bajo soberanía española en el norte de África, lo que dio pie a una protesta por parte de nuestro Estado "por violación de las "reglas del derecho internacional, universalmente reconocidas" (Cfr. Carta dirigida a la Embajada de Marruecos en Madrid con fecha 7 de febrero de 1976; reprod. en Atmane, 2007 a: 63).

${ }^{21}$ Ello no había impedido, sin embargo, que ya el 15 de marzo de 1976, el gobierno mauritano adoptara un Decreto por el que reestructuraba su organización administrativa para integrar en su seno el territorio del antiguo Río de Oro (Weexsteen, 1976: 270).

${ }^{22}$ Dahir portant ratification et publication de la convention relative au tracé de la frontière d'Etat établie entre la république islamique de Mauritanie et le Royaume du Maroc, signée à Rabat, le 14 avril 1976. BORM (3311 bis), 16/4/76; reprod. en Annuaire de l'Afrique du Nord, vol. 15, 1976, p. 849 (accesible asimismo en U.N.T.S., vol. 1035, I, n 15406).

23 Dahir portant ratification et publication de l'accord de coopération économique entre la république islamique de Mauritanie et le Royaume du Maroc pour la mise en valeur du territoire saharien récupéré, signée à Rabat, le 14 avril 1976. BORM (3311 bis), 16/4/76; reprod. en Annuaire de l'Afrique du Nord, vol. 15, 1976, p. 850. En desarrollo del Acuerdo el 2 de marzo de 1978 ambos estados firmaban un Protocolo de aplicación de los acuerdos en materia de pesca (Annuaire de l'Afrique du Nord, vol. 17, 1978, p. 692). 
Por su parte, Marruecos, adoptaba en su ordenamiento jurídico las medidas para integrar el territorio en su estructura administrativa, incorporando las provincias de Layounne (El Aaiún) y Es-Semara (Asmara) ${ }^{24}$. Este texto sería a su vez objeto de modificación el 14 de agosto de 1979 para incorporar el territorio abandonado por Mauritania. Sin embargo, un dato que merece particular atención es el hecho de que, pese a la caracterización que de sí mismo ofrece Marruecos como soberano territorial del Sáhara Occidental, la definición de sus espacios marítimos no ha estado presente ni en los actos unilaterales ni en los actos concertados con otros Estados u organizaciones, con la salvedad de los prematuros acuerdos mauritano-marroquíes. Así, en su ámbito interno Marruecos no ha adoptado disposiciones tendentes a acomodar el Dahir de 1975 a los espacios marítimos del Sáhara, observando en este punto las disposiciones heredadas del periodo de colonización española ${ }^{25}$.

Sin embargo, en 1981 la legislación marroquí estableció tanto una zona contigua como una zona económica exclusiva ${ }^{26}$. Por otra parte, Marruecos dispone de una regulación específica en materia de plataforma continental -que data de 1958- y que ha sido objeto de ulteriores modificaciones y desarrollos, tanto por disposiciones de Derecho interno como sobre la base de acuerdos de delimitación con otros Estados. En el primer caso se sitúan las ya mencionadas disposiciones de la Ley sobre la ZEE de 1981 así como la Legislación en materia de explotación de hidrocarburos ${ }^{27}$; al segundo responde el ya citado acuerdo con Mauritania, habiéndose iniciado en 2003 negociaciones con España para abordar la delimitación en el entorno de las islas Canarias, aunque sin reportar resultados hasta la fecha.

Esta última cuestión merece una consideración especial, pues debe recordarse que ya en 1988, en respuesta a una pregunta parlamentaria planteada en el Congreso de los Diputados en relación con la delimitación de los espacios marinos del archipiélago canario, el Gobierno español había advertido que:

La delimitación de las aguas españolas a partir de la costa canaria afecta también al territorio del Sáhara Occidental, por lo que no parece posible proceder a una delimitación estable y efectiva en tanto no se haya solucionado el conflicto que asola a esa zona y quede claro, una vez el pueblo saharaui haya ejercido su derecho a la autodeterminación, cuál es el status jurídico internacional del Sáhara Occidental $^{28}$

De hecho, este planteamiento ha sido mantenido ininterrumpidamente por España y ha sido reiterado ante la Comisión de Límites de la Plataforma Continental -establecida en el marco de la Convención de Naciones Unidas sobre Derecho del Mar, de 10 de diciembre

\footnotetext{
${ }^{24}$ Dahir portant loi $n^{\circ} 1-76-468$ du 9 chaabane 1396 (6 août 1976) modifiant le dahir $n^{\circ} 1-59-351$ du ler joumada II 1379 (2 décembre 1959) relatif à la division administrative du Royaume, BORM (3328) 11/8/76; reprod. en Annuaire de l'Afrique du Nord, vol. 15, 1976, p. 851.

${ }^{25}$ Ihraï, 2008: 113-114, si bien el autor se refiere incorrectamente al periodo del "Protectorado" español.

${ }^{26}$ Cfr. Dahir núm. 1-81-179, de 8 de abril, portant promulgation de la loi 1-81 instituant une zone économique exclusive de 200 milles marines au large des côtes marocaines, BORM núm. 3575, 6 de mayo de 1981.

${ }^{27}$ Dahir núm. 1-91-118, de 1 de abril de 1992, portant promulgation de la Loi no 21-90 relative à la recherche et exploitation des gisements d'hydrocarbures, BORM, 15 de abril de 1992. Dicho texto fue modificado ulteriormente por el Dahir núm. 1-99-340, de 15 de febrero de 2000 portant promulgation de la Loi no 27-99 modifiant et completant la Loi 21-90 relative à la recherche et exploitation des gisements d'hydrocarbures, BORM, 16 de marzo de 2000. Referencias extraidas de Atmane, 2007 a: 80.

${ }^{28}$ BOCG, CD, III Legislatura, Serie D, núm. 315, pp. 14830-14831; cit. en González Campos, 1989: 545.
} 
de $1982^{29}$ - con miras a preservar "los derechos de terceros que puedan ser reclamados en su día”, en una clara alusión al Sáhara Occidental ${ }^{30}$.

Finalmente conviene destacar que, pese a su singular situación ${ }^{31}$, los representantes legítimos del pueblo del Sáhara Occidental también han adoptado medidas relativas a los espacios marinos del territorio. En concreto, la República Árabe Saharaui Democrática aprobaba en 2009 una Ley, en la que reivindicaba sus derechos sobre el conjunto de los espacios marinos aledaños al territorio conforme a las normas internacionales ${ }^{32}$, cuyo texto era comunicado a las representaciones de los Estados miembros en las Naciones Unidas con una nota de 22 de enero de 2009, transmitida por el representante del Frente Polisario, el recientemente fallecido A. Jafari, en la que advertía que el Gobierno de la República Árabe Saharaui Democrática (RASD/SADR):

... considers illegal any activities related to the exploration or exploitation of the natural resources of the SADR territorial sea, exclusive economic zone or continental shelf conducted without its express authorization...,

The Government of the SADR reserves the right to pursue legal action in respect of any such unauthorized activities, ..., including those concluded between the Kingdom of Morocco and any third parties. ${ }^{33}$.

\section{EL EJERCICIO DE LAS COMPETENCIAS SOBRE LOS ESPACIOS MARINOS: LOS ACUERDOS DE PESCA (1975-2013)}

El derecho a la libre determinación económica respecto a los espacios marinos del territorio no autónomo encuentra también expresión en el ejercicio del ius ad tractatum en relación con la gestión de los recursos -particularmente los renovables- existentes en ellos. Este derecho sin embargo se ve afectado en el caso de los acuerdos concertados por terceros Estados sin la participación del pueblo titular del mismo. De ahí que convenga mencionar los desarrollos convencionales concluidos entre España y Marruecos, sustituidos -a partir de 1986- por los acuerdos concertados por la CEE/UE.

En el caso de nuestro país, éste venía manteniendo estrechas relaciones pesqueras con Marruecos, primero en el marco de las relaciones de vecindad y ajustadas a criterios de

\footnotetext{
${ }^{29}$ U.N.T.S., vols. 1833,1834 y 1835, p. 371.

30 Vid. inter alia, nota verbal de la Misión Permanente de España ante las Naciones Unidas, núm. 064 MPbcm, 7 de abril de 2015, accesible <http://www.un.org/depts/los/clcs_new/submissions_files/esp77_14/prt_re_esp77_spa.pdf>. respecto véase Martín y Pérez de Nanclares, 2016: 219-226, así como González Vega, 2016: 270).

${ }^{31}$ Hemos apuntado antes la incidencia que el caso palestino -tras el asunto Brita- ha tenido en el desarrollo de la estrategia jurídica del Frente Polisario. Aunque existen significativas diferencias, pues la OLP -a título de observador- participó en los trabajos de la III Conferencia sobre Derecho del Mar, firmando su Acta Final (Goy, 2005: 195); además, reconocido como Estado no miembro de Naciones Unidas, Palestina podría acceder a la condición de Parte en la Convención de 1982 y desarrollos conexos, conforme a la política iniciada en 2014 (Trigeaud, 2015: 571-604).

32 Law no. 03/2009, of 21 January establishing the Maritime Zones of Saharawi Arab Democratic Republic; disponible en <https://archive.org/details/327943-documents-268462-sahrawi-arab-democratic $>$. Un análisis de ésta en Riquelme Cortado, 2013: 385-489.

33 Nota de 22 de enero de 2009; accesible en <https://archive.org/details/327943-documents-268462sahrawi-arab-democratic $>$. Fue trasmitida por conducto de Independent Diplomat.
} 
reciprocidad, con posterioridad saldadas con sucesivos acuerdos concluidos en 1969 y $1973^{34}$; ninguno de ellos sin embargo aludía a las aguas del Sáhara Occidental -a la sazón bajo administración española- por cuanto era el acceso de los buques españoles a los caladeros marroquíes su razón de ser. La situación, no obstante, se modificó a raíz de los Acuerdos de Madrid de 14 de noviembre de 1975, en los que ante el inminente abandono del territorio por parte de España se acordaron disposiciones relativas al mantenimiento de las actividades pesqueras por buques españoles en el banco sahariano ${ }^{35}$. Empero, el Protocolo provisional de pesca con Marruecos de 29 de julio de 1979 dejaba sin efecto aquellas previsiones, asimilando en lo sucesivo las aguas del Sahara bajo ocupación marroquí a las aguas marroquíes, bajo la común referencia a las "aguas bajo jurisdicción marroquí’36.

Si bien estos compromisos suponían ya un reconocimiento de la jurisdicción marroquí sobre los espacios marinos del Sáhara Occidental por parte de nuestro país, ha de advertirse la honda polémica que rodeará la conclusión del Acuerdo de cooperación sobre pesca marítima entre España y Marruecos, firmado el 1 de agosto de 1983, al poder estimarse que conllevaba "el reconocimiento implícito por España de la soberanía marroquí sobre todo el Sáhara Occidental...a cambio, entre otras cosas de la explotación de los caladeros saharauis por los pesqueros españoles" (González Campos, 1989: 569) ${ }^{37}$. Cuestión que rebrotaría con motivo del Protocolo provisional de pesca de 23 de diciembre de 2002 -concluido con ocasión de la crisis del Prestige- y en el cual se autorizaba temporalmente a 64 buques españoles a faenar en aguas marroquíes, incluidas las aguas del Sáhara Occidental (García Rico, 2003: 511-515) ${ }^{38}$.

En cuanto a la UE, tampoco la conclusión de los sucesivos Acuerdos de pesca con Marruecos y su aplicación al Sáhara Occidental parece haber planteado dificultades, pese a las indudables implicaciones jurídicas que se derivan de ello: eventual reconocimiento tácito de la anexión -en abierta violación de una obligación derivada de una norma imperativa de derecho internacional- y vulneración de los derechos del pueblo saharaui a su soberanía sobre los recursos naturales (Casado y Gutiérrez, 2001: 212). De hecho, el primer acuerdo fue firmado en Rabat el 26 de mayo de 1987, aplicado provisionalmente desde el 1 de

\footnotetext{
34 Se trata respectivamente del Convenio sobre pesca marítima entre España y Marruecos de 4 de enero de 1969 (BOE, núm. 134, 5 de junio de 1969) y de las Actas de Rabat de 12 de mayo de 1973 y Casablanca de 23 de noviembre de 1973. En este último, España evitaba reconocer la zona de pesca de 70 millas proclamada por Marruecos ese mismo año, pero no veía preservados sus derechos históricos en materia pesquera (Sobrino Heredia, 1999-2000: 239).

35 La denominada Declaración de principios entre España, Marruecos y Mauritania sobre el Sáhara Occidental de 14 de noviembre de 1975 -no publicada en el BOE, pero sí en U.N.T.S., vol. 988, I, n 14450, a instancias de Marruecos- no contenía ninguna referencia al tema, aunque otros compromisos conexos sí la abordaban (Sobrino Heredia, 1999-2000: 238).

36 Protocolo de acuerdo transitorio en materia de pesca marítima entre el Gobierno del Reino de España y el Gobierno del Reino de Marruecos, hecho en Rabat el 29 de junio de 1979 (BOE, núm. 253, de 22 de octubre de 1979). Ulteriores acuerdos "transitorios y formales" reiterarían esta solución (Sobrino Heredia, 1999-2000: 238). Este protocolo venía a colmar la laguna producida por la inaplicación del acuerdo de 1974 y el fallido Acuerdo de cooperación en materia de pesca marítima de 17 de febrero de 1977, que no había llegado a entrar en vigor -a pesar de su ratificación por España- por la oposición de Marruecos ante la renuente actitud española respecto al Sahara (Naima, 2006: 34).

37 BOE, 11 de octubre de 1983.

${ }^{38}$ Conviene destacar la excepcionalidad de este acuerdo, al no existir relación convencional vigente entonces entre la UE y Marruecos tras la extinción del precedente en 1999 y el fracaso de las negociaciones de cara a uno nuevo (Ihraï, 2003: 135-150).
} 
marzo de 1988 y aprobado en nombre de la Comunidad el 23 de junio de $1988^{39}$. No obstante, como se ha destacado, su aplicación -conforme a lo dispuesto en el Protocolo núm. 1- planteó en su momento ciertos problemas en relación con las aguas adyacentes al Sahara Occidental (Olesti Rayo, 1995: 455). Con todo, el Acuerdo resultaba "mucho menos explícito sobre su ámbito de aplicación" que el precedente Acuerdo con España, al recurrir ambiguamente a las expresiones "aguas sometidas a la soberanía o a la jurisdicción del Reino de Marruecos", denominadas en lo sucesivo "zonas de pesca de Marruecos", distinguiendo dos grandes zonas de pesca situadas respectivamente al norte y al sur del paralelo $30^{\circ} 40^{\prime} \mathrm{N}$, permitiendo en la última de ellas las actividades pesqueras en una distancia superior a las 12 millas $^{40}$.

El segundo Acuerdo sobre las relaciones en materia de pesca marítima entre la CEE y el Reino de Marruecos fue rubricado el 15 de mayo de 1992 y aprobado en nombre de la CEE el 19 de diciembre de $1992^{41}$. En él, como en el precedente, el Protocolo al Acuerdo determinaba las posibilidades de ciertas modalidades de pesca (cerco, artesanal, cefalópodos, etc.) en la denominada zona sur -situada al sur del paralelo $28^{\circ}, 44^{\prime} \mathrm{N}$ - donde comienza precisamente el territorio del Sahara- incluyendo por consiguiente toda su franja costera hasta el límite con Mauritania; lo que confirmaban sus previsiones en materia de inspección de buques que contemplaban su realización en el puerto de Dakbla (antigua Villa Cisneros) (Olesti Rayo, 1995: 455).

De nuevo, la Comunidad y Marruecos firmaron el 13 de noviembre de 1995 un Acuerdo de cooperación en materia de pesca marítima, aprobado por la Comunidad el 12 de diciembre de $1996^{42}$. En éste, como en los precedentes se fijan las posibilidades de pesca de la flota comunitaria en las aguas que depende de la soberanía o de la jurisdicción de Marruecos $^{43}$, así como la correspondiente contrapartida por parte de la Comunidad que comprende, entre otras, una ayuda financiera destinada a desarrollar el sector pesquero marroquí.

Finalmente, tras el apuntado fracaso de las negociaciones para sustituir al Acuerdo de 1995, el 28 de julio de 2005 se rubricaría en Bruselas un nuevo Acuerdo de pesca -el cuarto- que entraría en vigor el 1 de marzo de 2006, tras su aprobación por el PE y el Consejo $^{44}$. Conforme a sus previsiones (art. 11 y Capítulo III del Apéndice al Anexo del Protocolo) se deduce su aplicabilidad a las aguas del Sáhara Occidental, a través de la conocida fórmula dicotómica de "las aguas sometidas a soberanía o a jurisdicción del Reino

\footnotetext{
39 Reglamento (CEE) n ${ }^{\circ}$ 2054/88, en virtud del cual quedó aprobado en nombre de la Comunidad dicho Acuerdo (DO L 181, 12 de julio de 1988, p. 1). Ya sobre el mismo se alertaba que el tratamiento de la cuestión del Sáhara Occidental respondía a la "variante pesquera del síndrome del avestruz" (Juste Ruiz, 1988: 741-764). El acuerdo sucedía al Acuerdo hispano-marroquí de 1983, extinto en julio de 1987, aunque prorrogado hasta diciembre de ese mismo año.

${ }^{40}$ Cfr. Art. 1 del Protocolo núm. 1 y apartado G) del Anexo I (DO L 99, 16 de abril de 1988); cit. en González Campos, 1989: 569.

41 Reglamento (CEE) n 3954/92 del Consejo de 19 de diciembre de 1992, relativo a la celebración del Acuerdo sobre las relaciones en materia de pesca marítima entre la CEE y el Reino de Marruecos, y por el que se adoptan disposiciones para su aplicación (DO L 407,31 de diciembre de 1992, p. 1).

42 Reglamento (CE) no 150/97 del Consejo de 12 de diciembre de 1996 relativo a la celebración del Acuerdo de cooperación en materia de pesca marítima entre la CE y el Reino de Marruecos y por el que se adoptan disposiciones para su aplicación (DO L 30, 31 de enero de 1997, p. 1). Sobre éste, Olesti Rayo, 1995: 453462.

43 Art. 2. Por otra parte, su Protocolo reitera idéntica previsión que el precedente acuerdo de 1992 respecto a la pesca en la zona atlántica meridional al sur del paralelo $28^{\circ} 44^{\prime} \mathrm{N}$.

${ }^{44}$ DO L 141, 29 de mayo de 2006. Para un estudio global del acuerdo véase per omnia González García, 2010: 521-563.
} 
de Marruecos, denominadas en lo sucesivo zona de pesca de Marruecos". De esta manera, las instituciones europeas consideraban que ello no entrañaba un reconocimiento de las reivindicaciones de soberanía marroquí sobre el territorio ${ }^{45}$. Por su parte, abundando en esta idea, el dictamen del Servicio jurídico del Parlamento Europeo de 26 de febrero de 2006 sostenía que no se podía afirmar a priori que Marruecos no respetaría la obligación derivada de la norma consuetudinaria sobre la libre determinación- de transferir las ventajas y, particularmente, los beneficios financieros derivados del Acuerdo a la población del Sáhara Occidental en tanto que titular del derecho exclusivo a la explotación de los recursos marinos vivos de las aguas saharauis. Semejante planteamiento, sin embargo, contrasta con el hecho de no preverse mecanismos efectivos para asegurar su cumplimiento en beneficio de la población -sólo una comisión mixta de aplicación (art. 10)y no contemplar mecanismos de suspensión o terminación en caso de incumplimiento grave (Andreone, 2007: 346; Soroeta Liceras, 2009: 823-864).

Frente a esta posición, aunque el Parlamento Europeo se ha mostrado más sensible en defensa de los derechos e intereses del pueblo saharaui (Torrejón Rodríguez, 2014) siendo expresivo de ello su negativa a autorizar el Protocolo de Pesca de 2011 sobre la base del previo Informe Haglund (Sobrino Heredia, 2012: 235-261; Torrejón Rodríguez, 2013: 127-141)- ha de recordarse que en su rechazo confluían preocupaciones ecológicas y financieras de algunos grupos políticos e indiferencia ante un acuerdo de escasa importancia para el conjunto de los Estados miembros (González Vega, 2016 b: 270). Por lo que no ha de extrañar que la institución parlamentaria "volviera al redil" con ocasión del ulterior Protocolo de 2013, sobre la base del previo Informe Robles Fraga, que se sitúa en el centro del asunto que nos ocupa. De hecho, la introducción de "cambios puramente cosméticos" junto con una "declaración retórica" sobre la eventual suspensión del acuerdo en el caso de una supuesta violación de los derechos humanos y de los principios democráticos, bastó para que aprobara un texto que era en sustancia idéntico al rechazado en 2011 (Soroeta Liceras, 2016 b: 218).

Obviamente, la actitud del Frente Polisario contrasta con los desarrollos precedentes. De hecho, el representante legítimo del pueblo saharaui ha denunciado constantemente los sucesivos acuerdos y que incluso durante un periodo de tiempo (19771987) -en los momentos más álgidos de su enfrentamiento militar con Marruecos- aún carente de legislación al efecto, adoptó medidas de carácter coercitivo con miras a afirmar su competencia exclusiva sobre los espacios marinos aledaños al territorio del Sáhara Occidental. Nos referimos a lo que cabría tildar de "diplomacia de la zodiac", concretada en numerosos incidentes -muchos de incierta autoría- que afectaron en aquel periodo a buques pesqueros que faenaban en las aguas saharianas (Soroeta Liceras, 2001: 231; González Vega, 2016 b: 268) ${ }^{46}$. En todo caso, con la adopción de la ya mencionada Ley de 2009 la RASD afirma su competencia para regular las actividades desarrolladas en sus

\footnotetext{
45 Los planteamientos de las partes a la hora de interpretar la fórmula eran, de un lado, la diversa condición soberanía y jurisdicción, respectivamente- del Mar Territorial y la ZEE (Marruecos); de otro, la soberanía reconocida a Marruecos sobre sus espacios marítimos frente a la mera jurisdicción -como administrador de facto- de las aguas adyacentes al Sáhara Occidental, respecto a las cuales el negociador jefe -en nombre de la UE- reconocía el ius ad tractatum en manos de Marruecos (Atmane, 2007 b: 138).

46 Pese a tratarse de operaciones militares en una "zona de guerra" no resulta difícil apreciar concomitancias con los coetáneos incidentes relacionados con el ejercicio de la "policía pesquera" frecuentes en la práctica de la época (Andrés Sáenz de Santa María, 1989: 7-41). Pese a ello, la Asociación Canaria de Víctimas del Terrorismo (ACAVITE) reclama su reconocimiento como tales por parte del Gobierno de España (cfr. <http://www.laopinion.es/canarias/2010/05/23/cruz-mar-asalto-nadie-reivindico/287092.html>), lo que parece cuestionable, dada la condición del Polisario como Movimiento de Liberación Nacional y la caracterización como "zona de guerra” del territorio (Palacios Romeo, 2013: 111-160).
} 
espacios marinos y autorizar -eventualmente mediante los consiguientes tratados- el acceso a los mismos.

\section{LAS POSICIONES DEL AG WHATELET, DE LAS INSTITUCIONES Y DE LOS ESTADOS MIEMBROS}

A tenor de lo expuesto parecían indudables las razones que asistían al AG cuando asumía la plena aplicabilidad del Protocolo de pesca de 2013 a las aguas del Sáhara Occidental al advertir que:

una interpretación del Acuerdo de pesca y del Protocolo de 2013 conforme con las normas de interpretación de los tratados enunciadas en el artículo 31 del Convenio de Viena sobre el Derecho de los Tratados lleva a la conclusión de que sí son aplicables al territorio del Sáhara Occidental y a las aguas adyacentes a dicho territorio ${ }^{47}$.

En orden a afianzar su apreciación, comenzaba señalando que, aunque los límites precisos de las zonas de pesca allí contempladas no figuraban concretados en ellos, los mapas aportados por la Comisión revelaban que las actividades pesqueras previstas abarcaban "hasta la frontera marítima entre la República Islámica de Mauritania y el Sáhara Occidental, cubriendo así las aguas adyacentes a este último"48. Añadía a todo ello que las informaciones facilitadas por la Comisión revelaban que el 91,5\% del total de capturas al amparo de los acuerdos se realizaban en las aguas saharauis, lo que demostraría:

Con claridad que desde un primer momento lo que las partes precisamente contemplaban es la aplicación a las aguas adyacentes al Sáhara Occidental tanto del Acuerdo de pesca como del Protocolo de 2013. ${ }^{49}$

Además, insistía, tanto de los precedentes acuerdos -incluidos los concluidos por España con anterioridad a su adhesión a la CEE- como de los actos realizados por Marruecos, así como de diferentes declaraciones realizadas por los Estados con ocasión de la conclusión del Protocolo de 2013 se desprendía claramente su aplicabilidad a las aguas adyacentes al Sáhara Occidental, por lo que instaba al Tribunal a determinar si tal circunstancia afectaba a "la legalidad" de los acuerdos, "a la luz del artículo 3 TUE, apartado 5, y de las normas del Derecho internacional" ${ }^{\prime 50}$.

Luego, con miras a concretar las normas de derecho internacional infringidas se libra a un pormenorizado examen en el que destaca, de un lado, la vinculatoriedad para la UE en cuanto al respeto del derecho a la libre determinación de los pueblos y el carácter plenamente justiciable de sus actos a la luz del mismo ${ }^{51}$, de otro, el necesario respeto al principio de la soberanía permanente del pueblo saharaui sobre sus recursos naturales, análisis que además proyecta a tenor de las normas del derecho internacional humanitario,

\footnotetext{
${ }^{47}$ Conclusiones de 10 de enero de 2018, EU:C:2018:1, pto. 62.

48 Ibid., pto. 69.

${ }^{49}$ Ibid., pto. 70.

${ }^{50}$ Ibid., pto. 75 .

${ }^{51}$ Ibid., ptos. 105-129.
} 
dado que considera no sólo la hipótesis de una administración de facto ejercida por Marruecos sino la eventualidad de una ocupación militar. Todo ello le lleva a concluir que:

... los actos impugnados, que son aplicables al territorio del Sáhara Occidental y a las aguas adyacentes, en tanto en cuanto están bajo la soberanía o jurisdicción del Reino de Marruecos, vulneran la obligación de la Unión de respetar el derecho del pueblo de dicho territorio a la libre determinación, así como su obligación de no reconocer una situación ilegal resultante de una vulneración de dicho derecho y de no prestar ayuda ni asistencia para el mantenimiento de la situación. Además, por lo que se refiere a la explotación de los recursos naturales del Sáhara Occidental, los actos impugnados no establecen las garantías que permitan asegurar que dicha explotación se realice en beneficio del pueblo de dicho territorio. ${ }^{52}$

Frente a este planteamiento, tanto el Consejo como la Comisión -apoyados por Francia, España y Portugal- defendían la aplicabilidad de los acuerdos a los espacios marinos concernidos, si bien, obviamente, sostenían que se trataba de actos plenamente válidos. Para ello, el Consejo y la Comisión -junto al Gobierno francés- aducían la condición de Marruecos como "potencia administradora de facto" del territorio, lo que le habilitaría para concertar acuerdos aplicables "al Sáhara Occidental y a las aguas adyacentes, sin conculcar el derecho de su pueblo a la libre determinación" ${ }^{\prime 5}$. En apoyo de esta idea, la Comisión precisaba que con independencia del régimen jurídico-internacional aplicable tratárase de la administración de un territorio no autónomo o de uno sometido a ocupación militar- la explotación de los recursos naturales del mismo habría de realizarse "en beneficio del pueblo del Sáhara Occidental",54, coincidiendo junto con el Consejo en que "las disposiciones del acuerdo de pesca, así como del Protocolo de 2013, son idóneas para garantizar que así ocurra efectivamente" 55 .

Por su parte, aun cuando no participara directamente en el procedimiento ${ }^{56}$, Marruecos favorecía desde los medios de comunicación gubernamentales una intensa campaña en la que incluso se equiparaban los efectos de una sentencia adversa ¡a una victoria para los independentistas catalanes! $!^{57}$.

\footnotetext{
52 Ibid., pto. 293.

53 Ibid., pto. 217. El AG advierte, sin embargo, que este último argumento no es refrendado por los Gobiernos español y portugués, "limitándose el Gobierno español a afirmar que Marruecos no es la potencia ocupante del Sáhara, sin precisar, sin embargo, en qué condición podría entonces celebrar” dichos acuerdos (Ibid., pto. 219).

54 Ibid., pto. 268.

55 Ibid., pto. 269.

56 Sí lo hacía, en cambio, veladamente, a través de la Confédération marocaine de l'agriculture et du développement rural (COMADER).

${ }^{57}$ Así, se hacían eco de la opinión del académico francés J.C. Martinez, quien advertía que: "Should the ECJ follow the Advocate General's recommendation in its judgement, this would set a dangerous precedent. Groups advocating Kurdish or Catalan independence will feel entitled to challenge the legality of treaties signed between the Commission and Turkey or Spain... Catalan NGOs, such as Esquerra Republicana, will predictably start challenging all treaties signed by Madrid and Brussels, because they apply de facto in Catalonia" (Cfr. <https://saharaquestion.com/en/news/morocco-eu-fisheries-deal-legal-experts-warn-against-ecj-meddling-internationaltreaties?utm_source $=$ SaharaQuestion + List\&utm_campaign $=\mathrm{f} 6 \mathrm{be} 81 \mathrm{dbb} 7$ -
}

RSS_EMAIL_CAMPAIGN\&utm_medium $=$ email\&utm_term=0_9778738cd5-f6be81dbb7374894205\&ct=t(RSS_EMAIL_CAMPAIGN)\&mc_cid=f6be81dbb7\&mc_eid=42508b6571>. Cursivas añadidas). 
Sin embargo, el Tribunal va a desatender las peticiones de unos y otros y va adoptar otro enfoque.

\section{EL ENFOQUE DEL TRIBUNAL: UNA VISIÓN FORMALISTA DEL ASUNTO}

En efecto, el Tribunal opta -lo había hecho ya en su anterior decisión- por una línea argumentativa que de generalizarse llevaría a hacer innecesario el control jurisdiccional en relación con la conformidad del derecho de la UE al derecho internacional, pues como veremos postula una interpretación en la que resulta inconcebible que un acuerdo pueda transgredir tales normas jurídicas; en la especie, ciertas normas del derecho internacional general.

Es cierto, que el Tribunal ha seguido la senda trazada en la sentencia de 2016, pero, conviene advertirlo, la semejanza del asunto no debe inducir a equívoco. En aquella se juzgaba la aplicabilidad y la eventual validez de un acuerdo que sólo de modo incidental afectaba a la cuestión del Sáhara Occidental, pese a que fuera el Frente Polisario el promotor del litigio. En este en cambio se trataba de unos acuerdos en los que su aplicabilidad a este territorio -o más precisamente a sus espacios marinos aledañosresultaba consustancial, pudiendo caracterizar tal empeño como su objetivo central.

Sin embargo, el Tribunal -animado por la estrategia planteada en su anterior decisiónpostulará la validez de los acuerdos, aunque ceñidos a una interpretación que distorsiona en absoluto el que ha sido hasta ahora su marco efectivo de aplicación.

\section{LA COMPETENCIA DEL TRIBUNAL PARA CONTROLAR LA VALIDEZ DE UN ACUERDO INTERNACIONAL EN VÍA PREJUDICIAL}

Llama la atención el hecho de que el Tribunal, al aceptar el envite del Abogado General, decida resolver la primera y no la segunda de las cuestiones prejudiciales subsistentes ${ }^{58}$. De hecho, esta última, requería de él que precisara:

si podía autorizarse a una persona jurídica cuya legitimación activa, como es el caso de la demandante de los asuntos principales, está acreditada en el Derecho interno a impugnar, por motivos basados en que la Unión haya infringido el Derecho internacional, la validez de acuerdos internacionales como el Acuerdo de Asociación, el Acuerdo de Colaboración y el Protocolo de 2013 y la validez de los actos por los que éstos se celebraron y aplicaron ${ }^{59}$

Lo que habría conducido inexorablemente a incidir en la cuestión de la invocabilidad por los particulares y, presumiblemente, a responder negativamente a la misma, tal como ya

\footnotetext{
58 Las dos primeras habían quedado desprovistas de objeto al incidir sobre la aplicación al territorio del Acuerdo de Asociación UE-Marruecos, descartada en la sentencia de 2016, por lo que, requerido el órgano jurisdiccional remitente, éste acordaba mantener sólo las dos últimas relativas respectivamente a la validez de los acuerdos y a su invocabilidad por los particulares recurrentes (Sentencia TJUE de 27 de febrero..., cit., apdo. 41)

59 Ibid., apdo. 38. Tal como veremos, la resolución del caso llevará al Tribunal a considerar innecesario responder a la misma (apdo. 87).
} 
hemos tenido ocasión de advertir (González Vega, 2018). De ahí, que haya podido sostenerse que al actuar así el Tribunal realiza "una singular inversión de las cuestiones de admisibilidad y de fondo" pues la respuesta a la primera no depende de la segunda e in extremis una respuesta negativa a aquella hubiera hecho innecesario resolver la cuestión de fondo (Simon, 2018: 9). Semejante proceder, abona la idea -sobre la que volveremos- de que el Tribunal obra de este modo para solventar de, una vez por todas, la "saga saharaui" ante las instancias jurisdiccionales europeas.

En todo caso, la cuestión competencial que se plantea el Tribunal va a ser resuelta de forma rotunda en un sentido favorable al ejercicio de sus poderes de control. Y es que se cuestionaba la posibilidad de que en el contexto de una cuestión prejudicial se pudiera abordar la validez de un tratado ("acuerdo internacional"). El hecho, ciertamente constituía una primicia, tal como se cuidaba de advertir el $\mathrm{AG}^{60}$; de ahí que a este planteamiento se opusiera frontalmente el Consejo al insistir en que sólo los actos de la UE relativos a su conclusión podían ser considerados por el TJUE y que la vía pertinente no habría de ser otra sino el oportuno recurso de anulación ${ }^{61}$, obviamente extemporáneo, a más de controvertido en punto a la legitimación.

Para el Tribunal, sin embargo, el tema no plantea dudas pues la competencia prejudicial atribuida se extiende a todos los actos de las instituciones "sin excepción alguna" 62 , de suerte que "los acuerdos internacionales celebrados por la Unión en virtud de lo dispuesto en los Tratados constituyen, por lo que respecta a la Unión, actos adoptados por sus instituciones" entrada en vigor, del ordenamiento jurídico de la Unión", debiendo ser "sus disposiciones" "plenamente compatibles con los Tratados y con los principios constitucionales que se derivan de ellos", tanto respecto a su contenido material como respecto a sus modalidades de celebración. ${ }^{64}$

No existiendo límites al ejercicio de su función jurisdiccional, el Tribunal afirma luego que su control se ejerce no sólo en cuanto a la conformidad de tales actos al derecho de la Unión -y en primer término obviamente respecto de sus normas supremas, los tratados constitutivos- sino también respecto de "las normas de Derecho internacional que, de conformidad con los mismos, vinculen a la Unión" ${ }^{65}$. Es cierto sin embargo que el Tribunal no admite que en el marco de la cuestión prejudicial se pueda cuestionar directamente la validez de un acuerdo concluido por la UE, aunque sí lo que podríamos denominar "por efecto reflejo" los actos de las instituciones por los que se autoriza su conclusión,

\footnotetext{
${ }^{60}$ Conclusiones..., cit., pto. 2.

${ }^{61}$ Sentencia TJUE de 27 de febrero de 2018, Western Sahara Campaign UK, C-266/16, EU:C:2018:118, apdo. 42 .

${ }^{62}$ Ibid., apdo. 44.

${ }^{63}$ Ibid., apdo. 45. En su apoyo cita las sentencias de 16 de junio de 1998, Racke, C-162/96, EU:C:1998:293, apdo. 41, y de 25 de febrero de 2010, Brita, C-386/08, EU:C:2010:91, apdo. 39.

${ }^{64}$ Sentencia TJUE de 27 de febrero..., cit., apdo. 46. Sus afirmaciones se acompañan con profusas citas; así, menciona las sentencias de 30 de abril de 1974, Haegeman, 181/73, EU:C:1974:41, de 22 de noviembre de 2017, Aebtri, C-224/16, EU:C:2017:880, de 3 de septiembre de 2008, Kadi y Al Barakaat International Foundation/Consejo y Comisión, C-402/05 P y C-415/05 P, EU:C:2008:461, así como los dictámenes 1/75 (Acuerdo OCDE - Norma sobre gastos locales), de 11 de noviembre de 1975, EU:C:1975:145 y 1/15 (Acuerdo PNR UE-Canadá), de 26 de julio de 2017, EU:C:2017:592.

${ }^{65}$ Sentencia TJUE de 27 de febrero..., cit., apdo. 48.
} 
permitiendo por esta vía un control que alcanza a la postre a aquéllos ${ }^{66}$; una solución que, como se ha destacado, sin ser evidente en sí misma, goza ya de un sólido refrendo jurisprudencial (Simon, 2018: 8).

En este punto, es obvio, el Tribunal asume pues -como avanzáramos en otro lugar (González Vega, 2018)- que las exigencias de la UE en tanto que Unión de Derecho también comprenden la sumisión de ésta a las normas internacionales y el consiguiente control de su respeto por parte del propio Tribunal. Además, descarta de raíz la eventual incidencia negativa de las evidentes connotaciones políticas del asunto, puestas de manifiesto por el AG, quien, sin embargo, excluía que pudieran tener por efecto impedir la intervención del Tribunal, pues:

Ciertamente, varias de las respuestas que habrán de darse a estas cuestiones tendrán ramificaciones políticas. Sin embargo, como ha declarado la Corte Internacional de Justicia, «el hecho de que una cuestión jurídica también presente aspectos políticos, "como, por la naturaleza de las cosas, ocurre con tantas cuestiones que surgen en la vida internacional", no basta para privarla de su carácter de "cuestión jurídica"...»"

De hecho, al asumir implícitamente el rechazo de la doctrina del acto político (Political Question Doctrine $)^{68}$, el Tribunal puede librarse a un análisis de los acuerdos donde será, en principio, el derecho internacional el canon de referencia. Anticipemos, sin embargo, que éste cobrará unos contornos singulares; algo que no ha de sorprender a los conocedores de las peculiares relaciones que ha venido tejiendo la jurisprudencia del Tribunal de Luxemburgo en su aproximación al ordenamiento jurídico internacional (Martín y Pérez de Nanclares, 2011: 254).

\section{2. ¿UN ANÁLISIS EN CUANTO AL FONDO? EL PECULIAR CONTROL JUDICIAL DEL RESPETO DEL DERECHO INTERNACIONAL APUD ART. 31.3.c) DE LA CONVENCIÓN DE VIENA}

Aunque al obrar de esta suerte, algunos ven en ello el abandono de la anterior visión meramente procedimental del papel del derecho internacional en manos del Tribunal, para arrostrar un enfoque "sustancialista" donde éste cobra un rol decisivo -línea en la que se situaría ya la sentencia de diciembre de 2016 (Rasi, 2017: 971-972)- tal apreciación no se ajusta a las circunstancias del caso pues como apreciaremos el análisis al que se brinda el Tribunal es absolutamente formalista, rehuyendo todo atisbo de aproximación a la realidad

\footnotetext{
${ }^{66}$ Ibid., apdo. 51. Sin embargo, el Tribunal no asume las afirmaciones del AG que le recordaba su precedente decisión Rosneft (C-72/15, EU:C:2017:236), donde el Tribunal advirtiera las exigencias inherentes a "un sistema completo de vías de recurso y de procedimientos destinado a garantizar el control de la legalidad de los actos de la Unión" (conclusiones..., cit., pto. 47). Recuérdese que en aquel asunto también era Whatelet el AG, postulando una ampliación del control jurisdiccional por el cauce de la cuestión prejudicial -sólo que referido a los actos de la PESC- que obtuvo el favor del TJUE (Al respecto véase Andrés Sáenz de Santa María, 2017: 871-903; Poli, 2017: 1799-1834).

${ }^{67}$ Conclusiones..., cit., pto. 3. La cita de la CIJ procede de su opinión consultiva de 9 de julio de 2004, Consecuencias jurídicas de la construcción de un muro en el territorio palestino ocupado (C.I.J. Recueil, 2004, p. 136, párr. 41). La mención es relevante pues acentúa las similitudes entre el caso saharaui y el palestino. Por otra parte, ya la sentencia del TG de 2015 había movido a Marruecos a denunciar lo que consideraba una decisión política (Ferrer Lloret, 2017: 59, n. 152).

${ }^{68}$ Desde el ya mencionado asunto Rosneft cierto sector doctrinal defiende la acogida de este constructo del Derecho estadounidense para limitar la competencia del TJUE en cuestiones relacionadas con la acción exterior (Lonardo, 2017: 571-588).
} 
y evitando conscientemente entrar en todo debate que obligue a considerar en cuanto al fondo las reglas de derecho internacional en cuestión. De esta suerte, el Tribunal elude el análisis de nociones como "territorio", "soberanía”, “jurisdicción”, "potencia administradora de facto", "potencia ocupante", etc. Y ni siquiera, pese al aparente peso que juega en su planteamiento el principio de libre determinación de los pueblos, juzga necesario ofrecer una lectura que arroje luz sobre su concreto valor normativo; menos aún se asocia a la noción de jus cogens que supuestamente es uno de sus rasgos más característicos, tal como apuntara implícitamente el AG en sus conclusiones ${ }^{69}$. En este sentido es pertinente destacar la llamativa ausencia de la referencia a la naturaleza erga omnes del principio de "autodeterminación" o su caracterización como "principio esencial" del orden jurídico internacional, presente en la sentencia de $2016^{70}$. De hecho, contrasta la "empatía iusinternacionalista" (Völkerrechtfreundlichkeit) que caracterizaban allí sus afirmaciones con la astenia de la presente decisión ${ }^{71}$.

En todo caso, una vez más el punto de partida en el enfoque del Tribunal es la idea de que la interpretación de los acuerdos debe de guiarse por las tantas veces citadas reglas del art. 31 de la Convención de Viena ${ }^{72}$. Sin embargo, al enfrentar el proceso, el Tribunal desdeña el orden allí establecido -texto y contexto- para primar un elemento "contextual externo" (Sorel y Boré Eveno, 2011: 825) al que ajustará su interpretación: las normas del derecho internacional ${ }^{73}$. Así, retomando los términos de su precedente sentencia de 21 de diciembre de 2016, sostiene que:

incluir el territorio del Sáhara Occidental en el ámbito de aplicación del Acuerdo de Asociación conculcaría determinadas normas de Derecho internacional general que son de aplicación a las relaciones de la Unión con el Reino de Marruecos, como son el principio de libre determinación — que se reitera en el artículo 1 de la Carta de las Naciones Unidas - y el principio de efecto relativo de los tratados — del que el artículo

${ }^{69}$ En tal sentido, Conclusiones..., cit., pto. 129. En nuestro precedente comentario ya advertíamos que Whatelet asumía implícitamente esta caracterización al retomar literalmente los términos del art. 41 del Proyecto de artículo sobre la responsabilidad del Estado por hechos internacionalmente ilícitos adoptado por la CDI en su $53^{\circ}$ período de sesiones (Cfr. Documentos Oficiales de la Asamblea General, $56^{\circ}$ periodo de sesiones, Suplemento no 10 (A/56/10). (González Vega, 2018: n. 26).

${ }^{70}$ Cfr. Sentencia de 21 de diciembre de 2016, cit., apdo. 88. Como se destacara, la decisión de 2016 ponía en valor las normas internacionales relevantes y se acompañaba de referencias tanto a las Resoluciones de Naciones Unidas como a los diferentes pronunciamientos de la CIJ sobre el tema (Díez Peralta, 2017: 4). En concreto, tras aludir a la caracterización presente en la opinión consultiva de la Corte de 26 de octubre de 1975 en el asunto del Sáhara Occidental y al reconocimiento del principio en el art. 1 de la Carta de las Naciones Unidas se afirmaba, con apoyo en el obiter dictum de la Corte en su sentencia de 30 de junio de 1995 en el asunto Timor Oriental (Portugal c. Australia) (I.C.J. Reports 1995, p. 90, párr. 29), que "Además, es un derecho invocable erga omnes y uno de los principios esenciales del Derecho internacional". Pero téngase en cuenta que, aunque la noción de obligación erga omnes está presente en las normas imperativas, no es privativa de éstas (Frowein, 2008: párr. 7), siendo conceptos diferentes (Picone, 2011: 411-424).

${ }^{71}$ Sobre la proyección de este enfoque en su anterior decisión, Kassoti, 2017 a: 339-356.

72 Convención de Viena sobre el Derecho de los Tratados, de 23 de mayo de 1969 (U.N.T.S., vol. 1155, p. 331); obviamente aplicadas por el Tribunal a título de derecho consuetudinario.

${ }^{73}$ Arranca aquí, como veremos, una interpretación sui generis de las reglas de la Convención, donde frente a la sutil y gradualizada lógica allí establecida, prioriza una lectura sistémica selectiva que tiene por efecto desvirtuar el natural proceso interpretativo (Kassoti, 2017 b: 23-42; Odermatt, 2017: 735-737). Y es que, aunque es cierto que las reglas de la Convención no establecen jerarquía, siendo moduladas tanto en manos del TJUE como de otras instancias jurisdiccionales (Aust et al, 2014: 75-112), no lo es menos que, pese a las divergencias, intentan fundar en el texto la base más sólida de la interpretación (Venzke, 2014: 50). 
34 del Convenio de Viena sobre el Derecho de los Tratados constituye una expresión concreta... ${ }^{74}$

Vaya por delante que en este párrafo -al modo del burgués gentilhombre- el Tribunal acude al "principio de integración sistémica" contemplado en el art. 31.3.c) de la meritada Convención, que prevé la consideración a efectos interpretativos de "toda norma pertinente de derecho internacional aplicable en las relaciones entre las partes". Esta opción resulta controvertida: es cierto que responde, de un lado, a la invitación que le dirigía el AG al enfatizar la relevancia de las exigencias anudadas al art. 3 TUE -revelando en este punto la autonomía de la función interpretativa construida desde la perspectiva del derecho europeo; de otro, esta opción va al encuentro de una orientación que, desdeñada largo tiempo, ha tendido a afirmarse gradualmente en la práctica internacional más reciente (Gardiner, 2012: 487) ${ }^{75}$. Y es que el recurso a dicho principio garantizaría la aproximación al "mundo real" en el proceso de interpretación y aplicación de los tratados, pues merced a la disposición contenida en el art. 31.3.c) de la Convención de Viena el intérprete partiría de una visión aséptica de la norma "para llegar a la convicción judicial de cómo la norma ha de ser entendida a la luz de otras normas"; de suerte que:

Interpretation as a whole allows the interpreter to start from the cave and reach the outside world to leave darkness and enter the light to go from uncertainties to judicial certainties (Merkouris, 2015: 304. Cursivas añadidas).

Sin embargo, las bondades asociadas con el principio contrastan con los resultados que en ocasiones ha podido deparar su empleo; en este punto baste recordar las severas críticas dirigidas a su utilización por la Corte Internacional de Justicia en su sentencia de 6 de noviembre de 2003 en el asunto de las plataformas petroliferas (República Islámica de Irán c. Estados Unidos de América), donde el resultado al que habría conducido sería tildado de "ilógico" (Gardiner, 2012: 500) ${ }^{76}$. De hecho, como se ha señalado, a la luz de este y otros desarrollos jurisprudenciales en los que ha jugado un papel destacado, el recurso a esta técnica interpretativa es "tarea difícil" exigiendo del juez:

salir de su papel de simple técnico del derecho sin transformarse en legislador internacional o en intérprete arbitrario de los derechos y obligaciones (Andrés Sáenz de Santa María, 2011: 374).

Retomando el análisis de la decisión, hemos de destacar que, pese a lo discutible de priorizar este criterio al abordar el proceso hermenéutico de los acuerdos, esa afirmación de principio no guía cabalmente su labor; de hecho, el Tribunal no va a estar muy atento a las implicaciones sistémicas en su proceso interpretativo. Por de pronto prescinde ahora de considerar expresamente la cláusula de aplicación espacial contenida en el art. 29 de la Convención de Viena, siendo así que es la disposición que hubiera debido de tenerse en cuenta a la hora de abordar la cuestión; como hiciera en su precedente sentencia de $2016^{77}$.

\footnotetext{
${ }^{74}$ Sentencia de 21 de diciembre de 2016, cit., apdos. 88 a 93, 100, 103 a 107 y 123.

75 Así, se sostiene que su empleo resulta insoslayable pues cuando se concluye un tratado no se pretende actuar en contra de las obligaciones previamente existentes (McLachlan, 2005: 290).

${ }^{76}$ I. C. J. Reports 2003, p. 161.

77 Sentencia de 21 de diciembre de 2016, cit., apdo. 87. Se ha cuestionado que el Tribunal evocara entonces la regla dado que ésta excluye a priori la aplicación extraterritorial de un tratado (Peifert, 2017: 1041). Sin embargo, el art. 29 no establece una presunción contra la extraterritorialidad (Milanovic, 2014: 190), pues,
} 
Por otro lado, merece la pena reparar en las normas de derecho internacional general que el Tribunal retiene a los efectos de su indagación y que -a su juicio- impiden una interpretación que subsuma el territorio del Sáhara Occidental en el ámbito de aplicación ratione loci de los acuerdos, dado que se trata, objetivamente, de normas de muy desigual valor que, sin embargo, a sus ojos reportan idéntica eficacia. Viene lo anterior a propósito de algunas interpretaciones que han visto en tales aseveraciones el alineamiento implícito de la curia de Luxemburgo con la doctrina del jus cogens. A decir verdad, el Tribunal -que hubiese podido seguir la inequívoca línea trazada por el AG en sus conclusiones- se limita a establecer los términos de un conflicto normativo -sin más calificativos- que le obliga a excluirlo en aras de una interpretación "legalista" de los acuerdos en causa ${ }^{78}$.

$\mathrm{Y}$ es que en este punto el Tribunal bien podría haber establecido la contrariedad entre los Acuerdos y el principio de libre determinación, como le invitaba a hacer el $\mathrm{AG}^{79}$. Sin embargo, imbuido de la idea de que las obligaciones que pesan sobre la UE hacen tal conflicto inimaginable -pues "conculcaría determinadas normas"- postula la, a su juicio, única interpretación legalmente posible. Es aquí, donde el Tribunal pone de manifiesto claramente la intención de preservar a ultranza la validez de los acuerdos en causa. Esfuerzo que redoblará con idéntico afán -como veremos más adelante- cuando haya de considerar los especiales criterios espaciales en ellos presentes.

En cuanto al efecto relativo de los tratados, su empleo por el Tribunal para excluir la hipótesis de la aplicación de los acuerdos al territorio del Sáhara Occidental sugiere, cuando menos, una relectura de dicha noción ${ }^{80}$. Y es que el efecto relativo de los tratados no entraña sino que un tratado no obliga a un tercero sin su consentimiento -planteando un problema de oponibilidad, que no de validez- pero no supone en sí mismo un límite a la aplicación espacial de un tratado más allá de los territorios de las partes; sostener otra cosa implicaría negar la eficacia extraterritorial de las normas, algo que no cabe admitir en modo alguno (Milanovic, 2014: 190) ${ }^{81}$. Bien es cierto que con su mención ${ }^{82}$ queda en pie la

además de su carácter dispositivo, las excepciones se sitúan en el centro de la disposición (Karagiannis, 2012: 308) y precisamente en ellas se cifraba el quid del asunto.

${ }^{78}$ En cuanto al valor que cobra la libre determinación en el pronunciamiento del Tribunal se ha extendido Hilpold, 2017: passim), aunque no compartimos la caracterización "poscolonial" que le atribuye por las razones que hemos sostenido en otro lugar (González Vega, 2016 a: 346-348).

${ }^{79}$ Conclusiones..., cit., pto. 293. Que no lo haga el Tribunal de Justicia es comprensible; ni siquiera la CIJ osó hacerlo en 1995 en el mencionado asunto de Timor Oriental, escondiéndose tras la argucia procesal del "tercero indispensable", lo que llevaba a hablar de la "falacia del discurso de la libre determinación" (Castellino, 2000: 213-226). Sobre su invocación en el asunto por parte de Consejo y Comisión -presente también en las cuestiones formuladas por el órgano jurisdiccional remitente (Sentencia de 27 de febrero de 2018..., cit., apdos. 38 y 41.b)- que rechazaba el AG (Conclusiones..., cit., pto. 57) véase González Vega, 2018. En todo caso, el Tribunal no para mientes en ella.

${ }^{80}$ Por de pronto, la regla ha sido concebida en el marco de las relaciones entre Estados, con fundamento en su soberanía y en el consensualismo inherente al Derecho internacional, por lo que su aplicabilidad a entidades no estatales se torna más problemática (Chinkin 1993: 39). Por otra parte, aciertan plenamente quienes en la Sentencia de 2016 -donde ya aparecía- veían el erróneo afán del Tribunal por conferirle una función interpretativa de la que carece, máxime cuando ve en él una prohibición inexistente (Dubuisson, Poissonnier, 2016: 610). De forma bien distinta, como revelara (p.e.) la misma práctica del Reino de Marruecos en relación con aquél, lo que suponía era la inoponibilidad a éste de los acuerdos concluidos por las potencias protectoras durante el periodo colonial (Ouazzani Chahdi, 1982: 310-311).

81 Quien recuerda que precisamente la regla del efecto relativo protege a los terceros Estados frente a groseras violaciones de su soberanía (p.e. intervención) pero no excluye per se la validez de un tratado aplicable a su territorio (ibid. Cursivas añadidas). Menos aún en el caso del Sáhara Occidental donde las magras garantías en materia de derechos humanos de las que pueden prevalerse los habitantes del territorio derivan precisamente 
incógnita planteada ya en 2016 por el Tribunal -y no despejada- acerca del tercero con capacidad convencional respecto al territorio: ¿La población del Sáhara Occidental? ¿El pueblo del Sáhara Occidental? ¿El Frente Polisario? ¿La República Árabe Saharaui Democrática? ¿El Reino de España? ${ }^{83}$

La alusión a nuestro Estado no resulta ociosa pues ya en sus anteriores conclusiones en el asunto C-104/16 P, el AG Whatelet había advertido las posibles responsabilidades de nuestro país -aun en la actualidad- como potencia administradora, al señalar que:

Es cierto que el Reino de España se considera descargado de toda responsabilidad de carácter internacional relativa a su administración del Sáhara Occidental desde el 26 de febrero de 1976. Sin embargo, no se puede excluir categóricamente que, a pesar de su renuncia, el Reino de España haya conservado conforme al Derecho internacional su condición de Potencia administradora y que, en tal condición, sea la única entidad que tiene la capacidad, incluso la obligación, de proteger, incluso a nivel jurídico, los derechos del pueblo del Sáhara Occidental, en particular su derecho a la libre determinación y su soberania sobre los recursos naturales de este territorio. ${ }^{84}$

\section{LA IMPOSIBLE APLICACIÓN DE LOS ACUERDOS PESQUEROS AL SÁHARA OCCIDENTAL: ¿UNA INEXISTENTE INTENCIÓN COMÚN DE LAS PARTES?}

Decíamos antes que el Tribunal ha evitado entrar en la valoración de la norma de la libre determinación de los pueblos y que de sus afirmaciones no se puede extraer un alineamiento -siquiera implícito- con su naturaleza imperativa. En este orden, sus afirmaciones ulteriores brindan un ejemplo expresivo de ello. De un lado, a propósito de la posibilidad -contemplada en el art. 31.4 de la Convención de Viena- de que los términos de un tratado confieran a éstos un "sentido especial" por voluntad de las Partes ${ }^{85}$, cuando sostiene que:

de la aplicación extraterritorial de los tratados de los que es parte Marruecos, sin perjuicio de la condición jurídica distinta del territorio (González Vega 2015: 267-270).

${ }^{82}$ La noción ya aparecía en la Sentencia de 21 de diciembre de 2016, apdos. 100 a 107. Creemos que su acogida deriva de la "perversa atracción" del asunto Brita -recurrentemente citado por el Tribunal en ésta y en la previa decisión de 2016- y donde sí resultaba pertinente toda vez que el caso interesaba a un conflicto entre compromisos convencionales, los respectivos Acuerdos de Asociación entre la UE, Israel y la Autoridad Palestina (Palestina) suscritos por diferentes sujetos internacionales, ergo con ámbitos de aplicación espacial claramente definidos y excluyentes. Esta singularidad está ausente en el caso pues "la Unión Europea no ha firmado —ni previsiblemente firmará- un acuerdo de estas características con el Frente Polisario, representante del Sáhara Occidental a todos los efectos" (Díez Peralta, 2017: 5).

${ }^{83} \mathrm{Y}$ es que, aunque sería verosímilmente el Frente Polisario el beneficiario, el Tribunal no osó siquiera señalarlo (Ferrer Lloret, 2017: 46). Sobre la cuestión en detalle vid. infra, n. 113.

${ }^{84}$ Conclusiones, 13 de septiembre de 2016, C-104/16 P, EU:C:2016:677, pto. 188. Cursivas añadidas.

85 Este es el nudo gordiano del asunto pues, pues como hemos destacado, la noción de "jurisdicción" es la clave en la que se ha apoyado desde 1986 en el caso de la CEE/UE -y desde 1975 en el caso español- la aplicación al Sáhara de los sucesivos acuerdos pesqueros con Marruecos. El término es posiblemente el más versátil del Derecho internacional y su frecuente empleo en los textos internacionales es parejo a su indefinición pudiendo cobrar diferentes sentidos en diferentes contextos (Yang, 2012). En todo caso, que se trata de un "sentido especial" del término queda claro en el hecho de que no es la noción de "jurisdicción" retenida en el art. 56.1.b) de la Convención de Naciones Unidas sobre derecho del Mar sino la noción más 
Sin embargo, por lo que se refiere a la expresión «las aguas bajo soberanía [...] del Reino de Marruecos» del artículo 2, letra a), del Acuerdo de Colaboración, debe señalarse que resultaría contrario a las normas de Derecho internacional a que se refiere el apartado 63 anterior, las cuales deben ser respetadas por la Unión y se aplican mutatis mutandis al caso de autos, subsumir bajo esa denominación en el ámbito de aplicación del Acuerdo de Colaboración las aguas adyacentes directamente a la costa del territorio del Sábara Occidental. Por consiguiente, la Unión no ha de ser partícipe de la intención que pudiera tener el Reino de Marruecos de subsumir bajo esa denominación las aguas en cuestión en ese mismo ámbito de aplicación. ${ }^{86}$

Repárese en la objeción que dirige el Tribunal cuando alerta de que "la Unión no ha de ser partícipe"; bien está que el Tribunal recuerde que las normas internacionales han de ser respetadas por la Unión, pero ¿Acaso tal consideración excluye que la Unión pudiera convenir algo que las contrariara? De otro modo ¿Qué sentido tiene un control de validez que siempre -conforme sostiene aquí el Tribunal- debería ver en los acuerdos internacionales actos rigurosamente conformes a las reglas jurídico-internacionales en que se enmarcan?

Otra de las muestras más evidentes de este enfoque se cifra en el capital párrafo que transcribimos:

Por lo que atañe a la expresión «las aguas bajo [...] jurisdicción del Reino de Marruecos» que figura en la misma disposición, el Consejo y la Comisión han contemplado entre otras posibilidades que pueda considerarse que el Reino de Marruecos es «potencia administradora de facto» o potencia ocupante del territorio del Sáhara Occidental y que esa calificación resulte relevante a la hora de fijar el ámbito de aplicación del Acuerdo de Colaboración. No obstante, sin que sea siquiera necesario analizar si la posible intención común de las partes del Acuerdo de Colaboración de dar a la expresión un sentido especial para tener en cuenta las circunstancias mencionadas hubiera sido conforme con las normas de Derecho internacional que vinculan a la Unión, baste señalar al respecto que en el presente asunto no puede en ningún caso hablarse de tal intención común, puesto que el Reino de Marruecos ha negado categóricamente ser potencia ocupante o potencia administradora del Sáhara Occidental..$^{87}$

Se plantea aquí la cuestión de si, al margen de las previas consideraciones literalistas en torno a las nociones de "soberanía" y "jurisdicción" retenidas por el Tribunal, el acuerdo podría resultar aplicable a las aguas del Sáhara Occidental con base en otros argumentos. Ciertamente esta es la clave, pues las anteriores nociones entrañaban unas implicaciones que ni la UE ni sus Estados miembros pretendían suscribir (léase, el reconocimiento de la soberanía marroquí sobre el territorio controvertido y sus espacios marinos) ${ }^{88}$.

lata del ejercicio de competencias por un Estado sobre un espacio con independencia de la existencia de un título territorial legítimo.

${ }^{86}$ Sentencia TJUE de 27 de febrero..., cit., apdo. 71. Cursivas añadidas.

${ }^{87}$ Ibid., apdo. 72. Cursivas añadidas.

88 Contra esta afirmación, M. Whatelet había sostenido en sus conclusiones en el precedente asunto Consejo/Front Polisario, C-104/16 P, que "la aplicabilidad (del acuerdo) implica de forma necesaria e inevitable el reconocimiento" (Cfr. Conclusiones de 13 de septiembre de 2016, EU:C:2016:677, pto. 85). Sin embargo, las salvedades con las que siempre se ha rodeado la relación con Marruecos por parte de las instituciones de la UE a propósito del Sáhara Occidental (véase más abajo) prueban lo contrario. De ahí lo infundado de apreciar contradicción entre las afirmaciones del TJUE y las de las instancias políticas de la UE 
La primera cuestión se centra en la noción de "potencia administradora de facto", un constructo derivado del controvertido "dictamen Corell", conforme al cual Marruecos ejercería "de hecho" unas competencias sobre el territorio del Sáhara Occidental -al modo y manera de las atribuidas a las Potencias administradoras de los territorios autónomos con unas exigencias anudadas a la idea de obrar en pro de los intereses de la población de dicho territorio en lo atinente a la explotación de sus recursos naturales ${ }^{89}$. Se trata, como apuntamos, de una caracterización polémica toda vez que semejante planteamiento choca con la circunstancia de que la única potencia administradora, España, ha resignado ilegalmente ${ }^{90}$ - sus funciones haciendo inviable el desarrollo de aquellas actividades en el sentido pretendido. $\mathrm{Y}$ aunque, ciertamente, Marruecos al ocupar el territorio ha podido presentarse como una "potencia administradora de facto», sin embargo, como se ha sostenido, tal aseveración es una falacia carente de todo fundamento en el Derecho internacional y en la práctica de las Naciones Unidas (Rodríguez Magdaleno, 2016: 245246).

La segunda, referida a la condición de potencia ocupante -entiéndase militar- del territorio resultaba políticamente más arriesgada, toda vez que parte de asumir la radical ilegalidad de la presencia marroquí. Se trataba, no obstante, de una de las alternativas esbozadas por Whatelet ${ }^{91} \mathrm{y}$, desde luego, se compadece con la situación realmente existente aun cuando el conflicto armado se encuentre temporalmente suspendido desde $1991^{92}$. En todo caso, una indagación por esa vía habría conducido a rechazar frontalmente la validez de los acuerdos, dadas las severas limitaciones inherentes a la occupatio bellica -en donde la explotación económica de los recursos se subordina a la sola y exclusiva necesidad militarlo que no acontece obviamente en el caso del Sáhara Occidental ${ }^{93}$.

Sea como quiera, ambas nociones habían sido evocadas por el AG a la hora de abordar la presencia y el control marroquí sobre el territorio y los espacios marinos aledaños y, desde luego, al menos la primera de ellas era el cauce explicativo que sustentaban tanto el Consejo como la Comisión para postular la aplicación de los acuerdos en causa a las aguas saharauis $^{94}$.

so pretexto que éstas habrían reconocido la soberanía marroquí sobre el Sáhara Occidental (El Ouali, 2017: 951).

${ }^{89}$ Vid. Carta de fecha 29 de enero de 2002 dirigida al Presidente del Consejo de Seguridad por el Secretario General Adjunto de Asuntos Jurídicos, Asesor Jurídico, Doc. NU, S/2002/161, 12 de febrero de 2002, párrs. 7 y 8. Su autor era el diplomático sueco Hans Corell.

${ }^{90}$ Sobre el alcance de las obligaciones de España y su eventual subsistencia, Ruiz Miguel, 2010: 319-322.

${ }^{91}$ Conclusiones..., cit., ptos. 234-255.

${ }^{92}$ No es casual el afán del Frente Polisario por comprometerse a aplicar el Protocolo adicional núm. I a los Convenios de Ginebra de 12 de agosto de 1949, relativo a la protección de las víctimas de los conflictos armados internacionales, hecho en Ginebra el 8 de junio de 1977, merced a la declaración unilateral depositada el 23 de junio de 2015 ante el Consejo Federal suizo apud su art. 96.3, ni la virulenta protesta marroquí, que hemos analizado en otro lugar (González Vega, 2016 a: 349-355).

${ }^{93}$ Vid. Rodríguez Magdaleno, 2016: 248-253.

${ }^{94}$ Esta posición -sustentada en el apuntado Dictamen Corell- ya era compartida por éstas al menos desde 2009 y fue explicitada en 2011 por la, entonces, Alta Representante, C. Ashton (Torrejón Rodríguez, 2017: 247-258). Sobre la misma volvía en 2015 el Comisario de pesca cuando advertía que: "Según la posición de las Naciones Unidas, que la UE acata, el Sáhara Occidental sigue figurando en la lista de Naciones Unidas como territorio no autónomo, por lo que se considera que Marruecos es actualmente la potencia administradora «de facto»". (Cfr. Respuesta del Sr. Vella en nombre de la Comisión a la pregunta del Sr. F. Maura Barandiarán (ALDE), E-006564-2015, 8 de julio de 2015). 
Sin embargo, el Tribunal no juzga necesario entrar en su análisis dado que no existe, a su juicio, una intención común -una caracterización compartida- de las partes acerca del espacio al que resultarían eventualmente aplicables las reglas de los acuerdos, toda vez que para la UE se trataría de un espacio sometido a "administración de facto" del Reino de Marruecos ${ }^{95}$, en tanto que para este último se trataría de espacios sometidos a su soberanía y jurisdicción. En suma, el Tribunal diluye con su lacónica afirmación el "acuerdo sobre el desacuerdo" en el que se ha cifrado la aplicación cuasi ininterrumpida de los sucesivos acuerdos pesqueros con Marruecos a las aguas del Sáhara Occidental a lo largo de los últimos 32 años.

El rigorismo del planteamiento no puede ser más rechazable: de un lado, porque como con carácter general se ha señalado los tratados internacionales son, en muchas ocasiones, actos concluidos por las partes en un contexto de profundo desacuerdo, presentándose usualmente como "a disgreement reduced to writing" (Klabbers, 2017:56), por lo cual la situación planteada no tenía nada de insólita. De otro, porque como recordara en el precedente asunto C-104/16 P, el AG Whatelet (y sus afirmaciones valen a maiore para el caso que analizamos):

el Consejo no ha aceptado tácitamente la interpretación del [Reino de] Marruecos de que el Acuerdo [de Liberalización] se aplica al Sáhara Occidental como parte de su territorio, lo que podría constituir un indicio de reconocimiento indirecto [de su soberanía]. Ha aceptado tácitamente que el Acuerdo [de Liberalización] se aplique también [...] a un territorio no autónomo que el Reino de Marruecos administra, lo que no implica ni reconocimiento ni aquiescencia ni aceptación. El Reino de Marruecos y la Unión son conscientes de que mantienen interpretaciones diferentes. They agree to disagree. Tienen un entendimiento mutuo según el cual la Unión admite la aplicación del Acuerdo en el territorio del Sáhara Occidental y el [Reino de] Marruecos no lo utiliza como argumento en apoyo de la reivindicación de su soberanía». ${ }^{96}$

Pero además de inconsistentes, las afirmaciones el Tribunal desafían toda lógica y desde luego -contra lo que sugieren los partidarios del enfoque sistémico- lejos de aproximarle al "mundo real" le enfrentan a la ominosa realidad. ¿Se puede pretender que una relación convencional cimentada en 32 años de sucesivos compromisos y cuya consecuencia ha sido la explotación de los ingentes recursos pesqueros del Sáhara ha estado falta en todo momento de una voluntad común? Sorprende desde luego tal constatación, máxime si se tiene presente que los costes económicos que ha reportado el acuerdo se han basado en una explotación de los recursos que no podían provenir -los números hablan- de otra zona que no fueran las aguas contiguas al Sáhara Occidental ${ }^{97}$. Pero para el Tribunal -que aquí sí

\footnotetext{
${ }^{95}$ En tal sentido, véase respuesta de la actual Alta Representante, F. Mogherini, en nombre de la Comisión, el 18 de febrero de 2016, a la pregunta formulada por Angela Vallina (GUE/NGL)- Consecuencias de la sentencia del TJUE sobre el Sáhara Occidental, 17 de diciembre de 2015, E-015923-15 (cit. en Díez Peralta, 2017: 7, n. 32). Adviértase que tal caracterización había sido sostenida previamente por el Consejo en sus alegaciones ante el TG (Cfr. Sentencia de 10 de diciembre de $2015 \ldots$, cit., apdo. 82).

${ }^{96}$ Conclusiones..., pto. 67.

${ }^{97}$ iQue se lo digan a los pulpos! Puede ser de interés el visionado del programa emitido por el canal de TV La Sexta donde se alerta acerca del origen de los supuestamente capturados en Marruecos y a la venta en nuestro país. Cfr. <http://www.lasexta.com/programas/equipo-investigacion/avances/es-siempre-pulpo-lo-que-nossirven-en-bares-el-adn-del-pulpo-el-viernes-en-equipo-deinvestigacion_201802285a96971a0cf2daf69121b741.html>.
} 
que se limita a ser "una simple boca que pronuncia las palabras de la ley" cierra la puerta a una declaración de invalidez que tal vez por ser considerada traumática para la posición exterior de la UE ha preferido excluir.

No obstante, restaba un último escollo para que la interpretación postulada por el Tribunal quedara asentada. En efecto, conforme al Anexo y al Apéndice 4 del mismo del Protocolo de 2013, el Departamento de Pesca Marítima del Reino de Marruecos habría de comunicar a la UE "las coordenadas geográficas de la línea de base marroquí y de la zona de pesca marroquí"; advirtiéndose en ellos que dicha comunicación habría de tener lugar respectivamente "antes de la fecha de aplicación" y "de la entrada en vigor" advertirá, sin embargo, que tal comunicación no tuvo lugar "hasta el 16 de julio de 2014" por lo que:

Teniendo en cuenta que el Protocolo de 2013 entró en vigor el 15 de julio de 2014, dichas coordenadas no forman parte del texto que acordaron las partes. ${ }^{100}$

El rigorismo del que hace prueba el Tribunal -descartar por 2 días la validez de la comunicación- es a todas luces extremo; baste para confirmarlo que la práctica internacional conoce de actos relacionados con la aplicación de los tratados -en entornos multilaterales además (p.e. el caso de las reservas tardías) ${ }^{101}$ - en los que no se impone tan severa conclusión. Si se piensa además que la ausencia de comunicación priva a los acuerdos de la concreción técnica requerida para su operatividad se aprecia con mayor rotundidad el exceso en que incurre el Tribunal.

Viene lo anterior a propósito del hecho de que las reglas contenidas en el art. 31 de la Convención de Viena, que el Tribunal afirma seguir, promueven una comprensión flexible del proceso interpretativo de un tratado, en el cual no sólo su texto y contexto, sino otros elementos pueden ser tomados en consideración a tales efectos. En concreto, dentro del ya mencionado "contexto externo", el art. 31.3.b) contempla la posibilidad de que, junto con el contexto, se tenga en cuenta:

toda práctica ulteriormente seguida en la aplicación del tratado por la cual conste el acuerdo de las partes acerca de la interpretación del tratado ${ }^{102}$

Sin que sea necesario un denodado esfuerzo hermenéutico para llegar a la conclusión de que esta previsión cubre con creces la situación planteada en el caso de la tardía nota de coordenadas, toda vez que como demostraban tanto las posiciones del Consejo como de la Comisión, la aplicación del protocolo se había guiado por aquélla, sin que se advirtiera objeción alguna a la demora registrada.

\footnotetext{
98 De acuerdo con la célebre frase "Mais les juges de la nation ne sont, comme nous avons dit, que la bouche qui prononce les paroles de la loi" (Montesquieu, 2015: 207).

99 Adviértase que se trata de expresiones con semejanza, aunque no idénticas, pues la primera admite la posibilidad una implementación del acuerdo, p.e. a través de la aplicación provisional, previa al momento de entrada en vigor del acuerdo.

100 Sentencia de 27 de febrero..., cit., apdo. 81.

101 Véase Guía de la Práctica sobre las Reservas a los Tratados; reprod. en Informe de la Comisión de Derecho Internacional $63^{\circ}$ período de sesiones (26 de abril a 3 de junio y 4 de julio a 12 de agosto de 2011), Naciones Unidas, Nueva York, 2011, pp. 183-194).

102 Amén de su flexible caracterización, la práctica ulterior es usualmente un aspecto clave en el proceso interpretativo (Aust, 2013: 215); de hecho, el AG le confería relieve en su argumentación (Conclusiones..., cit., pto. 74).
} 
De todas formas, no hay cuidado, ya que el Tribunal lo tenía todo bien atado, pues:

aun si se hubieran comunicado esas coordenadas antes de la entrada en vigor del Protocolo de 2013, en modo alguno habrían podido cuestionar la interpretación de la expresión "zona de pesca marroquí» que figura en el apartado mencionado ni ampliar el ámbito de aplicación del Protocolo de 2013 mediante la inclusión de las aguas adyacentes al territorio del Sáhara Occidental. ${ }^{103}$

$Y$ es que -como se afirma que dijera Talleyrand- "lo que no puede ser no puede ser y, además, es imposible” en la peculiar óptica jurídica que asume el Tribunal ${ }^{104}$.

\section{EL TRIBUNAL Y LA GUERRA DE LOS MUNDOS: CONCLUSIONES Y ELUCUBRACIONES}

Como se desprende de las líneas anteriores el TJUE ha asumido el control de unos acuerdos controvertidos seguramente con la intención de zanjar definitivamente un episodio -la saga judicial del Sáhara Occidental- que ha venido crispando las relaciones políticas y económicas entre la UE y su privilegiado partenaire, el Reino de Marruecos ${ }^{105}$. Podría haberlo evitado de haber alterado el orden de las cuestiones sometidas y haber considerado negativamente, presumimos, las cuestiones de invocabilidad de los particulares -promotores del recurso ante el tribunal británico- que yacían en el fondo del asunto. No ha querido y en su decisión es muy probable que haya pesado la intención de dejar bien claro -a las puertas está el recurso promovido por el Frente Polisario contra los mismos acuerdos cuyo desenlace cabe ya imaginar- la inanidad de perseguir la nulidad de éstos.

Esta opción podría ser tildada de valerosa, máxime si se conjuga con las afirmaciones que dedica la sentencia a la amplitud del control jurisdiccional en cuanto a los acuerdos internacionales, desmintiendo las pretensiones restrictivas del Consejo y de los Estados miembros. Con ellas el Tribunal prosigue su denodado esfuerzo por ensanchar los cauces del control judicial respecto a la acción exterior de la UE en todos sus frentes, fortalececiendo la dimensión internacional del concepto de Unión de Derecho consustancial a la propia UE. Las exigencias inherentes a la condición de la UE como potencia normativa cobran, merced al Tribunal, todo su sentido.

Pero si el arrojo del Tribunal en este punto es meritorio, más dudas ofrece la vía de análisis seguida luego para afrontar el examen de la cuestión. Situado entre la Escila de la validez de los acuerdos defendida por las instituciones y la Caribdis de su nulidad postulada -meritoriamente y con buenos argumentos de derecho internacional- por el AG, el Tribunal ha decidido cerrar los ojos a la realidad y postular una validez que sin duda a nadie contenta. Su argumentación en este orden reposa en una aprehensión sistémica de los acuerdos en liza que, pese a pretenderse fundada en los principios del derecho internacional, aboca a una lectura rígidamente formalista que torna imposible -aun cuando

\footnotetext{
${ }^{103}$ Sentencia de 27 de febrero..., cit., apdo. 82.

104 No aparece aquí la disquisición entre aplicación de jure ("aplicación legal”, aplicación jurídica") y aplicación de facto que sí había estado presente en su decisión de 2016 (apdos. 121, 125 y 26. Al respecto véase Ferrer Lloret, 2017: 46).

105 Ya las implicaciones de su previa decisión de 2016 eran juzgadas con preocupación por quien veía tras ellas una perturbadora influencia sobre la futura acción exterior de la UE (Hilpold, 2017: 920).
} 
haya sido no menos real- la aplicación espacial sostenida -y ejecutada ya- por las instituciones con el concurso de Marruecos y hace inviable la nulidad instada por el AG a la que desprovee en apariencia de todo fundamento en un meticuloso, pero escasamente convincente análisis, absolutamente alejado del mundo real ${ }^{106}$, desvirtuando por ende los objetivos a los que supuestamente hubiera debido de conducir la mencionada interpretación sistémica. Desde esta perspectiva, como no ver en ello una función "pseudodiplomática" (Ferrer Lloret, 2017: 46) a la que se brinda el Tribunal, en detrimento de su función judicial ${ }^{107}$.

Ciertamente, en su decurso el Tribunal ha recordado una vez más la relevancia que cobra el respeto por parte de la UE de las exigencias derivadas del derecho internacional, particularmente, las establecidas por las normas generales de este ordenamiento que vinculan a la UE. Y dentro de ellas el respeto al principio de la, ahora, libre determinación ${ }^{108}$ debe ser de nuevo saludado -aunque su vigor se vea un tanto atenuado frente a la rotundidad que revelara su anterior decisión de 2016. Queda por ver, sin embargo, cuáles son las consecuencias que se derivan a efectos prácticos de la imposible contradicción, en el universo normativo en que se mueve el Tribunal, entre aquellas normas y los acuerdos en cuestión y la consiguiente aplicación -por consiguiente, irregular - que de los mismos se ha hecho en el mundo real a lo largo de numerosos años.

Y es que si conforme a lo expuesto los vigentes acuerdos de pesca con el Reino de Marruecos no son aplicables a las aguas del Sáhara Occidental ergo las actividades extractivas realizadas por los pesqueros de los Estados miembros y los productos de la

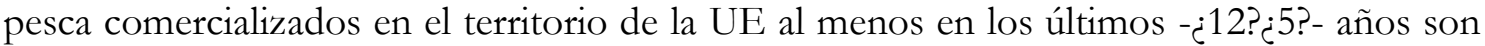
el resultado de una actividad ilegal que abre la vía para el eventual ejercicio de acciones judiciales con fundamento en la responsabilidad extracontractual de la $\mathrm{UE}^{109}$. No es el objeto del presente comentario indagar en tales posibilidades; limitémonos a consignar que el Frente Polisario ya ha advertido de las implicaciones -sin concretar por el momento las medidas a adoptar- que depara el fallo del pasado 27 de febrero ${ }^{110}$. En cambio, lo que sí es indudable es que arreciarán las acciones judiciales contra otros acuerdos entre la UE y Marruecos que planteen problemas similares; en tal sentido, es evidente que así habría de ocurrir con el Acuerdo Euromediterráneo de Aviación entre la Comunidad Europea y sus Estados miembros, por una parte, y el Reino de Marruecos, por otra, toda vez que en él se dispone, a efectos de su aplicación, que ha de entenderse por:

\footnotetext{
${ }^{106}$ Con ocasión de su anterior decisión se había destacado la "sorprendente ignorancia de la práctica" de que hacía gala el Tribunal", que al mismo tiempo apreciaba en el obrar del Consejo una "candidez" incapaz de atribuirle una violación de las normas internacionales (Delile, 2017: 182).

$107 \mathrm{Y}$ es que si la interpretación es una empresa política antes que una ciencia (Klabbers, 2017: 58), se encuentra ceñida a unos sutiles límites -máxime en el caso de la interpretación sistémica propugnada- que, de traspasarlos, distorsionan la función judicial.

108 Consecuencias de la traducción, el Tribunal hablaba de autodeterminación en su sentencia de 2016, ahora emplea en cambio el término libre determinación.

109 No consideramos aquí las cuestiones de la responsabilidad internacional que están a maiore absolutamente ausentes en el caso. De hecho, ya no lo estaban en su anterior decisión de 2016, pese a que sus afirmaciones entonces lo hacían factible (Ferrer Lloret, 2017: 47-50).

${ }^{110} \mathrm{Su}$ representación ante la oficina de Naciones Unidas en Ginebra remitía el 2 de marzo de 2018 una nota verbal en tal sentido a todas las representaciones permanentes allí radicadas. Más explícito, el letrado francés G. Devers, que viene asesorando al Frente Polisario en los procedimientos introducidos por éste en Luxemburgo, anunciaba que solicitaría a la Comisión una indemnización de 240 millones $€$ a título de responsabilidad por la pesca ilegal en las aguas saharauis (Cfr. Cembrero, 2018).
} 
«territorio»: por lo que respecta al Reino de Marruecos, las zonas terrestres (continente e islas), aguas interiores y mar territorial bajo su soberanía o jurisdicción... ${ }^{11}$

Más aún, siguiendo con los futuribles, en el punto de mira se encontrarán -a no tardarlos textos que deparen las negociaciones para la revisión del acuerdo de pesca con Marruecos de 2006 y el futuro Protocolo correspondiente, toda vez que el mandato negociador aprobado por el Consejo el pasado mes de marzo ${ }^{112}$, aun cuando dictado teniendo presente la sentencia que comentamos y consciente de la necesidad de "aclarar el alcance geográfico del Acuerdo", no excluye la posibilidad de su aplicación "a las aguas adyacentes al Sáhara Occidental", pese a afirmar la necesidad de garantizar "la estricta observancia del Derecho internacional" ${ }^{\text {"113 }}$.

Por otra parte, augurábamos en otro lugar que el contencioso sobre los acuerdos pesqueros con el Reino de Marruecos preludiaba "tiempos interesantes" en el futuro -más incierto aún- de la cuestión del Sáhara Occidental (González Vega, 2018). Baste recordar que el pasado 18 de abril un centenar de universitarios e investigadores de diferentes nacionalidades publicaban en un diario francés de resonancias míticas -L'Humanité- un manifiesto reclamando al Presidente, E. Macron, un giro radical en la política francesa sobre el territorio, aduciendo, entre otros argumentos, el fallo que comentamos del Tribunal de Justicia ${ }^{114}$, lo que no ha sido óbice para que la reciente Resolución adoptada por el Consejo de Seguridad sobre el tema no depare ningún cambio significativo al respecto ${ }^{115}$.

Entretanto, más factible es esperar que los ciudadanos y las organizaciones de la sociedad civil que han venido apoyando incansablemente los legítimos derechos del pueblo

\footnotetext{
111 Art. 1, apdo. 15. El Acuerdo es objeto de aplicación provisional desde el 12 de diciembre de 2006, fecha de su firma (DO L 386, 29 de diciembre de 2006, p. 55), aunque sólo recientemente se han concretado los actos con miras a su entrada en vigor (Cfr. Decisión (UE) 2018/146 del Consejo de 22 de enero de 2018, sobre celebración del mismo, DO L 26, de 31 de enero de 2018, p. 4).

112 En realidad, su aprobación había tenido lugar como punto A (actividad no legislativa) en el Consejo de Agricultura y Pesca del 21 de febrero de 2018 (Cfr. <http://www.consilium.europa.eu/media/32731/19-agria-items-legislative.pdf $>$ ), pero obviamente hubo de ser revisado a la luz de la sentencia que comentamos.

113 Recomendación de Decisión del Consejo por la que se autoriza a la Comisión a entablar negociaciones en nombre de la Unión Europea con vistas a modificar el Acuerdo de colaboración en el sector pesquero con el Reino de Marruecos y celebrar un Protocolo, Bruselas, 21 de marzo de 2018, COM(2018) 151 final; texto accesible en $<$ https://eur-lex.europa.eu/legalcontent/ES/TXT/HTML/?uri=CELEX:52018PC0151\&from=EN>). De hecho, el mandato negociador insiste en los planteamientos sugeridos por la Comisión con anterioridad a la sentencia (Simon, 2018: 10) y su supuesto respeto pretende colmarse ahora con que "la población afectada por el Acuerdo haya intervenido adecuadamente en ép', introduciendo "los mecanismos adecuados para garantizar que la Comisión esté suficientemente informada e implicada en la distribución geográfica y social de los beneficios socioeconómicos establecidos por el Acuerdo y su Protocolo, de forma que la Comisión pueda asegurarse de que ambos benefician a la población afectada" e incluso contemplando la inclusión de una "cláusula de revisión que permita tener en cuenta una solución, aceptable para ambas partes, que contemple la autodeterminación del pueblo del Sáhara Occidental, en consonancia con los principios y objetivos de la Carta de las Naciones Unidas" (Ibid., cursivas añadidas). Pero, sin ánimo de profundizar en un debate hoy por hoy meramente especulativo restan algunas interrogantes: de un lado ¿Es la población afectada el tercero afectado por los acuerdos o lo es el pueblo del Sáhara Occidental? Por otra parte, dado que el Tribunal ha evocado el jus ad tractatum del Sáhara Occidental al recordar el principio del efecto relativo de los tratados ¿Se ve satisfecho con la "intervención" de la población afectada en los futuros acuerdos o ha de consentir en obligarse por ellos? Repárese que en este último caso se requiere un sujeto de derecho internacional y una población no lo es.

114 Texto accesible en <https://www.humanite.fr/la-france-une-lourde-responsabilite-dans-la-nondecolonisation-du-sahara-occidental-654034>.

115 Cfr. Doc. NU, S/RES/2414 (2018), de 27 de abril de 2018.
} 
saharaui -y una de las cuales ha sido la inductora de la presente decisión- intensifiquen sus campañas para denunciar y perseguir la explotación ilegal de los recursos naturales del Sahara Occidental. Y es que ellos, como las microscópicas e insignificantes bacterias en la novela de H.G. Wells que da título al presente comentario ${ }^{116}$, han sido los que han acabado con el relato que venía justificando hasta ahora el expolio de las ingentes riquezas naturales del banco pesquero sahariano.

\section{BIBLIOGRAFÍA}

Andreone, G. (2007). La nouvelle génération des Accords de pêche conclus par la Communauté Européenne avec les pays tiers. Annuaire du Droit de la Mer, 12, 325:347.

Andrés Sáenz de Santa María, P. (1989). Incidentes pesqueros y recurso a la fuerza. Estudio del apresamiento de buques pesqueros como medida de ejecución en el régimen internacional de pesquerías, Revista Española de Derecho Internacional, 61 (1), 7-41.

Andrés Sáenz de Santa María, P. (2011). El principio de integración sistémica y la unidad del Derecho Internacional. En A.J. Rodrigo, C. García (eds.). Unidad y Pluralismo en el Derecho internacional público y en la Comunidad internacional (Coloquio en homenaje a Oriol Casanovas, Barcelona, 21-22 de mayo de 2009) (pp. 356-374). Madrid: Tecnos.

Andrés Sáenz de Santa María, P. (2017). Mejorando la Lex Imperfecta: Tutela judicial y cuestión prejudicial en la PESC (a propósito del asunto Rosneft). Revista de Derecho Comunitario Europeo, 58, 871-903.

Atmane, T. (2007 a). España y Marruecos frente al Derecho del Mar. Oleiros: Netbiblo.

Atmane, T. (2007 b). El Acuerdo pesquero entre la UE y Marruecos de 28 de julio de 2005. En J.M. Sobrino Heredia (coord.). Mares y Océanos en un mundo en cambio: Tendencias jurídicas, actores y factores (XXI Jornadas de la Asociación Española de Profesores de Derecho internacional y Relaciones internacionales, A Coruña, 22-24 de septiembre de 2005) (pp. 133-139). Valencia: Tirant lo Blanch.

Aust, A. (2013). Modern Treaty Law and Practice, $3^{\mathrm{a}}$ ed. Cambridge: Cambridge UP.

Aust, H.P., Rodiles, A., Staubach, P. (2014). Unity or Uniformity? Domestic Courts and Treaty Interpretation. Leiden Journal of International Law, 27, 75-112.

Carro Martínez, A. (1976). La descolonización del Sáhara. Revista de Politica Internacional, 144, 11-38.

Casado Raigón, R., Gutiérrez Castillo, V.L. (2001). Maroc et Espagne. La délimitation de leurs espaces maritimes. Annuaire du Droit de la Mer, 6, 195-217.

Castellino, J. (2000). International Law and Self-Determination. La Haya-Boston-Londres: Martinus Nijhoff.

Cembrero, I. (2018), El Polisario libra en Canarias su nueva batalla contra el control marroquí del Sáhara, El Confidencial, 18-2-2018. Disponible en <https://www.elconfidencial.com/mundo/2018-03-14/canariassahara-polisario-vuelos-marruecos-ue_1535193/> consultado el 10 de mayo de 2018.

Chinkin, C. (1993). Third Parties in International Law. Oxford: Clarendon Press.

Cortés Marín, J.M. (2010). Tribunal de Justicia de la Unión Europea: Jurisprudencia del TJUE, Enero-Abril 2010. Revista de Derecho Comunitario Europeo, 36, 626-631.

116 "And scattered about it, ... were the Martians - DEAD! — slain by the putrefactive and disease bacteria against which their systems were unprepared; slain as the red weed was being slain; slain, after all man's devices had failed, by the bumblest things that God, in his wisdom, has put upon this earth". (Wells, H.G., The War of the Worlds, Harper Collins, Londres, 2017 (e.o., 1924), pp. 182-183. Cursivas añadidas). 
Delile, J.F. (2017). Les effets de la coutume internationale dans l'ordre juridique de l'Union Européenne, Cabiers de Droit Européen, 53, 178-183.

Díez Peralta, E. (2010). ¿Made in Israel? Reflexiones en torno al etiquetado de mercancías fabricadas en los territorios palestinos ocupados: a propósito de la sentencia Brita del TJUE, de 25 de febrero de 2010. Revista General de Derecho Europeo, $21 . \quad$ Disponible en $<$ http:/ / revistas.laley.es/content/Revista.aspx?params=H4sIAAAAAAAEAMtNLCIJLbL1 yy8JdVXLBXO8 Uyttg1zDPINDHAGxunEdHgAAAA==WKE $>$.

Díez Peralta, E. (2017). El Sáhara Occidental: una piedra en el camino de la asociación privilegiada entre la Unión Europea y Marruecos. La Ley Unión Europea, 46, 2017. Disponible en <http://www.iustel.com/v2/revistas/detalle_revista.asp?id_noticia $=409313 \& d=1>$.

Dubuisson, F., Poissonier, G., (2016). La Cour de Justice de l’Union Européenne et la question du Sahara Occidental: Cachez cette pratique (illégale) que je ne saurais voir. Revue Belge de Droit International, 48: 599-634.

El Ouali, A. (2017). L’Union Européenne et la question du Sahara: entre la reconnaissance de la souveraineté du Maroc et les errements de la justice européenne. European Papers, 2 (3), 923-951.

Ferrer Lloret, J. (2017). El conflicto del Sáhara Occidental ante los Tribunales de la Unión Europea. Revista General de Derecho Europeo, 42, 15-64. Disponible en <http://www.iustel.com/v2/revistas/detalle_revista.asp?id_noticia $=418727>$.

Fleury Graff, Th. (2016). Accords de libre échange et territoires occupés. À propos de l'arrêt TPIUE, 10 décembre 2015, Front Polisario c. Conseil. Revue Générale de Droit International Public, 120, 263-291.

Frowein, J. (2008). Obligations erga omnes. En Max Planck Encyclopedia of Public International Law. Disponible en <http://opil.ouplaw.com/view/10.1093/law:epil/9780199231690/law-9780199231690-e1400>.

García Rico, E.M. (2003). Las preguntas formuladas al Gobierno por J. A., Labordeta sobre la autorización a barcos gallegos para pescar en aguas 'del antiguo Sáhara español', comentarios a una respuesta incompleta. Revista Española de Derecho Internacional, 55 (1), 511-515.

Gardiner, R.N. (2012). The Vienna Convention Rules on Treaty Interpretation. En D.B. Hollis (ed.). The Oxford Guide to Treaties (pp. 475-506). Oxford: Oxford UP

González Campos, J.D. (1989). Práctica española de Derecho internacional público. Revista Española de Derecho Internacional, 41 (2), 545-569.

González García, I. (2010). Los acuerdos comunitarios de pesca con Marruecos y el problema de las aguas del Sáhara Occidental. Revista Española de Derecho Europeo, 36, 521-563.

González Vega, J.A. (2015). Pasado, presente... ¿y futuro? del respeto de los derechos humanos en el Sáhara occidental: Apuntes desde España. Ordine Internazionale e Diritti Umani, 2 (2), 250-272. Disponible en <http://www.rivistaoidu.net/sites/default/files/Gonzalez3.pdf>.

González Vega, J.A. (2016 a). El derecho del pueblo saharaui a la libre determinación y el «derecho de resistencia» frente a la ocupación marroquí. En Observatorio Aragonés para el Sáhara Occidental, (coord.). Sahara Occidental: Cuarenta años construyendo resistencia (pp. 323-366). Zaragoza: Pregunta Ediciones.

González Vega, J.A. (2016 b). A Bridge over Troubled Waters (and Sands)? A Critical Sight on Spain's Role in Western Sahara Issue 40 years Later. Spanish Yearbook of International Law, 20, 255-277.

González Vega, J.A. (2018). El Sahara Occidental, de nuevo, en Luxemburgo: Las implicaciones de una Unión de Derecho, también internacional. La Ley Unión Europea, 56: 1-12. Disponible en $<$ http://revistas.laley.es/content/Revista.aspx?params=H4sIAAAAAAAEAMtNLCIJLbL1 yy8JdVXLBXO8 Uyttg1zDPINDHAGxunEdHgAAAA==WKE>.

Gordon, N., Pardo, S. (2015). The European Union and Israel's Occupation: Using Technical Customs Rules as Instruments of Foreign Policy. Middle East Journal, 69, 74-90.

Gosalbo Bono, R. (2016). El Frente Polisario, las normas del Derecho internacional y el derecho de la Unión Europea. Revista de Derecho Comunitario Europeo, 53, 21-77. 
Goy, R., (2005). La Palestine et la Mer. Annuaire du Droit de la Mer, 10, 193-208.

Guarino, G. (2012). Il Territorio della Palestina alla Luce della Sentenza della CGUE Brita GMBH. Studi in memoria di Luigi Sico (pp. 691-717). Nápoles: Editoriale Scientifica.

Harpaz, G., Ruinson, E. (2010). The Interface between Trade, Law and Politics and the Erosion of Normative Power Europe: Comment on Brita. European Law Review, 35, 551-570.

Hart, D. (2015). Western Sahara goes to Europe. UK Human Rights Blog, 23 de octubre de 2015. Disponible en <https://ukhumanrightsblog.com/2015/10/23/western-sahara-goes-to-europe/>.

Hilpold, P. (2017). Self-determination at the European Courts: The Front Polisario Case" or "The Unintended Awakening of a Giant. European Papers, 2 (3), 907-921.

Ihrai, S. (2003). Le Non-renouvellement en 2001 de l'accord de pêche Maroc/Union Européenne. Annuaire du Droit de la Mer, 6, 135-50.

Ihraï, S. (2008). Les lignes de base marocaines. Annuaire du Droit de la Mer, 13, 111-121.

Juste Ruiz, J. (1988). El acuerdo pesquero CEE-Reino de Marruecos de 25 de febrero de 1988. Revista de Instituciones Europeas, 15, 741-764.

Hummelbrunner, S., Prickartz, A.C. (2016). It's Not the Fish that Stinks! EU Trade Relations with Morocco Under the Scrutiny of the General Court of the European Union. Utrecht Journal of International and European Law, 32: 19-40. Disponible en <https://www.utrechtjournal.org/articles/10.5334/ujiel.322/>.

Karagiannis, S. (2012). The Territorial Application of Treaties. En Hollis, The Oxford Guide to Treaties, cit. (pp. 305-327).

Kassoti, E. (2017). The Front Polisario v. Council Case: The General Court, Völkerrechtsfreundlichkeit and the External Aspect of European Integration (First Part). European Papers, 2 (1), 339-356.

Kassoti, E. (2017). The Council v. Front Polisario Case: The Court of Justice's Selective Reliance on International Rules on Treaty Interpretation (Second Part). European Papers, 2 (1), 23-42.

Klabbers, J. (2017). International Law, $2^{\mathrm{a}}$ ed. Cambridge: Cambridge UP.

Lonardo, L. (2017). The Political Question Doctrine as Applied to Common Foreign and Security Policy. European Foreign Afffairs Review, 22, 571-587.

Martín y Pérez de Nanclares, J. (2011). Unidad y pluralismo en la jurisprudencia del Tribunal de Justicia de la Unión Europea. Hacia un refuerzo de la autonomía del derecho de la Unión Europea frente al Derecho Internacional En Rodrigo, García (eds.). Unidady Pluralismo en el Derecho internacional..., cit. (pp. 254-286).

Martín y Pérez de Nanclares, J. (2016). Plataforma continental ampliada al oeste de las Islas Canarias: presentación española ante la comisión de límites de la plataforma continental. Revista Española de Derecho Internacional, 68 (1), 219-226.

McLachlan, C. (2005). The Principle of Systemic Integration and Article 31(3)(c) of the Vienna Convention. International and Comparative Law Quarterly, 54, 279-320.

Merkouris, P. (2015). Article 31 (3) c VCLT and the Principle of Systemic Integration. Leiden-Boston: Brill-Nijhoff.

Milano, E. (2017). Front Polisario and the Exploitation of Natural Resources by the Administrative Power. European Papers, 2 (3), 953-966.

Milanovic, M. (2014). The spatial dimension: Treaties and territory. En C.J. Tams, A. Tzanakopoulos y A. Zimmermann (eds.). Research Handbook on the Law of Treaties (pp. 186-221). Cheltenham-Northampton: Edward Elgar.

Montesquieu (2015), De l'esprit des lois (e.o. 1748). París: Ligaran. Disponible en <file://C:/Users/Powerot/Downloads/Montesquieu $\% 20-\% 20 \mathrm{De} \% 201 \% 20$ esprit $\% 20 \mathrm{des} \% 201$ lois365.pdf $>$. 
Naima, E.M. (2006). Análisis de los acuerdos hispano-marroquíes y sus efectos en las relaciones económicas y comerciales entre Marruecos y España (1956-2003) (tesis doctoral), Facultad de CC. Económicas, Universidad Autónoma de Madrid. Disponible en <https://repositorio.uam.es/handle/10486/1668>.

Odermatt, J. (2017). Council of the European Union v. Front Populaire pour la Libération de la Saguia-ElHamra et Du Rio de Oro (Front Polisario). American Journal of International Law, 111, 731-738.

Olesti Rayo, A. (1995). El Acuerdo de cooperación en materia de pesca marítima entre la Comunidad Europea y el Reino de Marruecos de 13 de noviembre de 1995. Revista Española de Derecho Internacional, 47 (2), 453-461.

Ouazzani Chahdi, H. (1982). La pratique marocaine du droit des traités. Essai sur le droit conventionnel marocain. París: LGDJ.

Palacios Romeo, F. (2013). El Frente Polisario bajo el estatuto de Movimiento de Liberación Nacional. En torno a la vulneración de derechos fundamentales, estrategia de criminalización y banalización del hecho terrorista. En F. Palacios Romeo (coord.). El derecho a la libre determinación del pueblo del Sábara Occidental. Del ius cogens al ius abutendi (pp. 111-160). Cizur Menor: Aranzadi.

Pastor Ridruejo, J.A. (2009). Curso de Derecho internacional público y Organizaciones internacionales, 13a ed., Madrid: Tecnos.

Peifert, O. (2017). La recevabilité d'un recours en annulation devant les jurisdictions européennes au prisme des règles coutumières d'interpretation des traités (Observations sous l'arrêt CJUE, 21 décembre 2016, Conseil c. Front Polisario, C-104/16 P, ECLI:EU:C:2016:973. Revue Générale de Droit International Public, 121, 1031-1048.

Picone, P. (2011). The Distinction between Jus Cogens and Obligations Erga Omnes. En E. Cannizzaro (ed.). The Law of Treaties beyond the Vienna Convention (pp. 411-424). Oxford: Oxford UP.

Poissonier, G., Dubuisson, $\quad$ F. La question du Sahara occidental devant le Tribunal de l'Union européenne:une application approximative du droit international relatif aux territoires non autonomes. Journal de Droit International, 143, 503-522.

Poli, S. (2017). The Common Foreign Security Policy after Rosneft: Still imperfect but gradually subject to the rule of law. Common Market Law Review, 54: 1799-1834.

Rasi, A. (2017). Front Polisario: A Step Forward in Judicial Review of International Agreements by the Court of Justice? European Papers, 2 (3), 967-975.

Riquelme Cortado, R. (2013). La soberanía permanente del pueblo saharaui sobre sus recursos naturales. En Cursos de Derecho internacional de Vitoria-Gasteiz 2011 (pp. 385-489). Madrid: Tecnos.

Rodríguez Magdaleno, R. (2016). La explotación de los recursos del Sahara Occidental. En Sahara Occidental: Cuarenta años construyendo resistencia..., cit. (pp. 235-256).

Ruiz Miguel, C. (2010). Las obligaciones legales de España como potencia administradora del Sahara Occidental. Anuario Español de Derecho Internacional, 26, 303-331.

Simon, D. (2018). Applicabilité des accords entre l'Union européenne et le Royaume du Maroc au territoire du Sahara occidental. Acte II. Europe, 28 (4), 6-10.

Simon, D., Rigaux, A. (2016). Le tribunal et le droit international des traités: un arrêt déconcertant. Europe, 26 (2), 5-11.

Simon, D., Rigaux, A. (2017). Le Front Polisario devant la Cour de justice: une résolution logique, mais des questions rémanentes. Europe, 27 (2), 5-9.

Sobrino Heredia, J.M. (1999-2000). Les relations de pêche entre l'Union Européenne et le Maroc: La recherche d'un nouveau modèle d'accord de pêche. Espaces et Resources Maritimes, 13, 232-257. 
Sobrino Heredia, J.M. (2012). Les relations euro-marocaines concernant la pêche. En A. Valle Gálvez (dir.). Inmigración, Seguridad y fronteras problemáticas de España, Marruecos y la Unión Europea en el área del estrecho (pp. 235261). Madrid: Dykinson.

Sorel, J.M., Boré Eveno, V. (2011). Article 31. Convention of 1969. En O. Cortén y P. Klein (eds.). The Vienna Conventions on the Law of Treaties. A Commentary, vol. I (pp. 804-837). Oxford: Oxford UP

Soreta Liceras, J. (2001). El conflicto del Sáhara Occidental, reflejo de las contradicciones y carencias del Derecho internacional. Bilbao: Servicio Editorial de la Universidad del País Vasco.

Soreta Liceras, J. (2009). La posición de la Unión Europea en el conflicto del Sahara Occidental, una muestra palpable (más) de la primacía de sus intereses económicos y políticos sobre la promoción de la democracia y de los derechos humanos. RDCE, 34, 823-864.

Soreta Liceras, J. (2016 a). La sentencia de 10 de diciembre de 2015 del Tribunal General de la UE (T512/12), primer reconocimiento en vía judicial europea del estatuto del Sahara Occidental y de la subjetividad internacional del Frente Polisario, Revista General de Derecho Europeo, 38. Disponible en $<$ http://www.iustel.com/v2/revistas/detalle_revista.asp?id_noticia $=417010>$.

Soreta Liceras, J. (2016 b). The Conflict of Western Sahara after Forty years of Occupation: International Law versus Realpolitik. German Yearbook of International Law, 59, 187-221.

Soreta Liceras, J. (2017). La cuestión de la legalidad de la explotación de los recursos naturales del Sáhara Occidental ante el Tribunal de Justicia de la Unión Europea. En C. Martínez Capdevila, E.J. Martínez Pérez (eds.). Retos para la acción exterior de la Unión Europea (pp. 73-93). Valencia: Tirant lo Blanch.

Torrejón Rodríguez, J.D. (2013). El Parlamento Europeo, el Sáhara Occidental y el Acuerdo de pesca de 2006 entre la Unión Europea y Marruecos, Revista de Investigaciones Políticas y Sociológicas, 12: 127-141. Disponible en <http://www.usc.es/revistas/index.php/rips/article/view/1579/1528>.

Torrejón Rodríguez, J.D. (2014). La Unión Europea y la cuestión del Sáhara occidental. La posición del Parlamento Europeo, Madrid: Reus.

Torrejón Rodríguez, J.D. (2017). Aspectos recientes de la acción exterior de la Unión Europea ante el conflicto del Sáhara Occidental ¿Qué papel para la Unión Europea y para España? En J. Alcaide Fernández, E.W. Petit de Gabriel (eds.). España y la Unión Europea en el orden internacional (pp. 247-258). Valencia: Tirant lo Blanch.

Trigeaud, L. (2015). L'influence des reconnaissances d'État sur la formation des engagements conventionnels. Revue Générale de Droit International Public, 119, 571-604.

Venzke, I. (2014). How Interpretation Makes International Law. On Semantic Changes and Normative Twists. Oxford UP.

Weexsteen, R. (1976). La question du Sahara Occidental. Annuaire de l'Afrique du Nord, 15, 255-275.

Yang, X. (2012). Jurisdiction. Oxford Bibliographies. Disponible en <http://www.oxfordbibliographies.com/view/document/obo-9780199796953/obo-9780199796953-

0030.xml>. 